BNL-61981

Informal Report

\title{
HYDRONIC DISTRIBUTION SYSTEM COMPUTER MODEL
}

OCTOBER 1994

Prepared for:

Office of Building Technologies

Building Equipment Division

U.S. Department of Energy

Washington, DC 20585

\section{Energy Efficiency \\ and Conservation Division}

DEPARTMENT OF APPLIED SCIENCE

BROOKHAVEN NATIONAL LABORATORY UPTON, LONG ISLAND, NEW YORK 11973

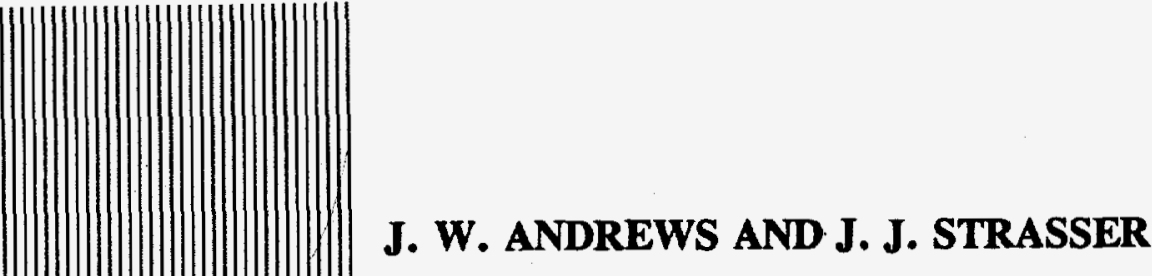




\section{DISCLAIMER}

This report was prepared as an account of work sponsored by the United States Government. Neither the United States nor the United States Department of Energy, nor any of their employees, nor any of their contractors, subcontractors, or their employees, makes any warranty, express or implied, or assumes any legal liability or responsibility for the accuracy, completeness, or usefulness of any information, apparatus, product or process disclosed, or represents that its use would not infringe privately owned rights. 


\section{DISCLAIMER}

This report was prepared as an account of work sponsored by an agency of the United States Government. Neither the United States Government nor any agency thereof, nor any of their employees, make any warranty, express or implied, or assumes any legal liability or responsibility for the accuracy, completeness, or usefulness of any information, apparatus, product, or process disclosed, or represents that its use would not infringe privately owned rights. Reference herein to any specific commercial product, process, or service by trade name, trademark, manufacturer, or otherwise does not necessarily constitute or imply its endorsement, recommendation, or favoring by the United States Government or any agency thereof. The views and opinions of authors expressed herein do not necessarily state or reflect those of the United States Government or any agency thereof. 


\section{DISCLAIMER}

Portions of this document may be illegible in electronic image products. Images are produced from the best available original document. 


\section{HYDRONIC DISTRIBUTION SYSTEM COMPUTER MODEL}

J. W. Andrews and J. J. Strasser

\section{Energy Efficiency and Conservation Division Department of Applied Science Brookhaven National Laboratory}

October 1994

Under Contract No. DE-ACO2-76CH00016 with the U.S. Department of Energy 


\section{ABSTRACT}

A computer model of a hot-water boiler and its associated hydronic thermal distribution loop has been developed at Brookhaven National Laboratory (BNL). It is intended to be incorporated as a submodel in a comprehensive model of residential-scale thermal distribution systems developed at Lawrence Berkeley Laboratory (LBL). This will give the combined model the capability of modeling forced-air and hydronic distribution systems in the same house using the same supporting software. This report describes the development of the BNL hydronics model, initial results and internal consistency checks, and its intended relationship to the LBL model. A method of interacting with the LBL model that does not require physical integration of the two codes is described. This will provide capability now, with reduced up-front cost, as long as the number of runs required is not large. 


\section{TABLE OF CONTENTS}

Abstract . . . . . . . . . . . . . . . . . .

List of Figures . . . . . . . . . . . . . . . . . . . iii

List of Tables . . . . . . . . . . . . . . . . . iii

Introduction . . . . . . . . . . . . . . . . . . 1

Interaction with the LBL Model . . . . . . . . . . . . 3

Approach to Hydronic System Modeling . . . . . . . . . . 5

Model Description . . . . . . . . . . . . . . . 6

Results of Preliminary Runs . . . . . . . . . . . . . 14

Model Operation with a Series of Hourly Heating Loads. . 18

Recommended Future Work . . . . . . . . . . . . . . 22

Appendix 1. Essential Algorithms . . . . . . . . . . 23

Appendix 2. Hydronic Program Code . . . . . . . . . . . . 34

References . . . . . . . . . . . . . . . . . . 54 


\section{LIST OF FIGURES}

Figure 1. Schematic representation of the IBL thermal distribution model

Figure 2. Intended interaction of the hydronic submodel with the LBL model . . . . . . . . . . . . . . . . 4 Figure 3. Hydronic Loop Divided into Sections . . . . . 8 Figure 4. HYDRO Program Flow Chart. . . . . . . . . . 9 Figure 5. LOADCURVE Program Flow Chart. . . . . . . . . 9 Figure 6. Boiler water and pipe temperatures, insulated pipe. . . . . . . . . . . . . . . . . . 15

Figure 7. Boiler water and pipe temperatures, uninsulated pipe . . . . . . . . . . . . . . . . . 15 Figure 8. Hydronic Efficiency vs. Heating Load. . . . . 21 Figure Al-1. Temperatures in pipes for the end-points approach . . . . . . . . . . . . . . . . . . 33

Figure A1-2. Temperatures in pipes for the block approach . . . . . . . . . . . . . . . . . . . 33

\section{LIST OF TABLES}

Table 1. Energy Balances for Six Cases . . . . . . . . . 17

Table 2. Energy Balances on Boiler and Thermal

Distribution System

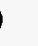

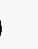




\section{INTRODUCTION}

As part of its responsibility to promote energy efficiency in buildings, the U.S. Department of Energy (DOE) has an interest in the efficiency with which thermal energy (heat or cooling) is transported from the equipment in which the heat or cooling effect is produced to the building spaces in which it is used. The systems that transport this energy are usually called thermal distribution systems. In the United States today, the most common type of thermal distribution systems in residential and small commercial buildings is the forced-air system that employs ductwork to distribute air that is moved by a fan. A recent government survey [RECS 1990] disclosed that in 1990, 53\% of households were served by a central warm-air furnace and a forced-air distribution system. Another 7\% were served by heat pumps, nearly all of which use forced-air systems to distribute their output energy. Thus, a clear majority of existing housing uses forced-air distribution systems.

The next most common type of distribution system is one that uses pipes to distribute hot water or steam to the building spaces. This type of system is usually called hydronic. In 1990, these systems served $15 \%$ of households.

Although forced-air systems have captured the bulk of the space-conditioning market in the United states, there is nevertheless great interest in hydronic systems for the following reasons:

- They are the second-largest category of thermal distribution systems in existing housing today.

- They are believed to have potential for very high efficiency if constructed with this in mind.

With regard to this second point, the high efficiency potential for hydronic systems derives from the fact that they avoid some of the loss factors commonly met with in forced-air systems:

1. Leakage. Duct systems often have leakage rates in excess of $10 \%$ of flow. Hydronic systems cannot leak without disastrous consequences to the building; therefore leaks are prevented for reasons other than energy efficiency.

2. System effects. Duct systems are subject to losses through various kinds of system interactions, such as an increase in the air infiltration rate of the house when the fan comes on, and thermosyphoning in the duct system when the fan is off. Hydronic systems do not have a fan, and the hydrodynamics of most piping systems usually prevents thermosyphoning. 
3. Conductive losses. Both pipes and ducts conduct heat through their containment walls. Ducts, however, are larger than pipes and therefore heat conduction will be greater, all else being equal. They are also harder to insulate than pipes because of their greater cross-sectional area.

These things being said, it must also be noted that hydronic systems can produce losses of their own. For one thing, many piping systems are not insulated where they pass through unconditioned spaces. For another, the equipment efficiency may be greatly reduced in certain types of systems that come under the heading "hydronic," such as single-pipe steam systems. Also, condensing furnaces with Annual Fuel Utilization Efficiencies (AFUE) above $90 \%$ can be easily linked to forced-air systems, but because of the higher return-water temperatures usually found in hydronic systems, the maximum seasonal efficiencies of hot-water boilers, even if designed to support condensing, may be expected to fall in the $85 \%-89 \%$ range.

All these considerations having been noted, there is strong reason to believe that a well-designed hydronic system that is well insulated where it passes through the unconditioned space and that uses an efficient hot-water boiler can easily achieve an overall system efficiency in excess of $80 \%$, where system efficiency is defined as the ratio of heating load to fuel used. Forced-air systems, if properly designed and installed can achieve similarly high efficiencies, but as commonly implemented in practice, they may commonly produce system efficiencies below 50\%. [ASHRAE 1992]

To evaluate the potential for hydronic systems to provide an efficient alternative to forced air, at least two scientifically useful paths are possible:

- Side-by-side field evaluations of efficient embodiments of both forced-air and hydronic systems, possibly in conjunction with simultaneous evaluations of "run-of-the-mill" versions of both systems.

- Development of a simulation model that would permit an "apples-to-apples" comparison of the two system types in the same house under the same weather conditions.

Because the second alternative was judged to be much the less expensive, it was chosen as the first DOE-sponsored effort relating to hydronic systems. To capitalize on work that had already been undertaken, the Lawrence Berkeley Laboratory (LBL) model of forcedair systems was chosen as the platform on which a hydronic modeling capability would be added. Brookhaven National Laboratory (BNL) was chosen to develop a hydronic submodel that could be incorporated into the LBI thermal distribution model. 


\section{INTERACTION WITH THE LBL MODEL}

Since the hydronic systems model described here is intended to be incorporated in the LBL model, a brief description of this model is appropriate. A complete description is best given by the model's originators [Treidler et al. 1993], but we need to give a brief account sufficient to understand the relationship of the hydronic submodel (developed by us) to the intended main model developed at $L B L$.

The LBL model is based on the widely used building simulation program DOE-2, but in addition it has subprograms that provide more accurate predictions of air flows driven by pressure and temperature differences (subprogram COMIS) and duct heat- and masstransfer dynamics (subprogram DUCTSIM) than are available in the standard DOE-2 package.

Figure 1 shows this schematically. DOE-2 generates the building-space temperatures and heating (cooling) loads that have to be met by the equipment and distribution system. comIs then computes the air flows that would be encountered in both the ducts and the zones of the house under fan-on and fan-off conditions. DUCTSIM uses this information to simulate the hour's running of the equipment and distribution system necessary to meet the given load.

The LBL model can also be run without ducts. When running without ducts, the LBL model replaces the DUCTSIM program with a simple routine that just meets the loads as calculated by DOE-2 without perturbing the system in any way. LBL's "no-ducts" energy supply meets the loads supplied by DOE-2 without depending on any thermal distribution system at all, which in the heating mode is conceptually equivalent to having individual heating systems in each zone.

So far we have not discussed how the LBL model accounts for interactions between the duct system and the space-conditioning load. That is, if heat is lost from ducts to a basement, and this heat serves to reduce the amount of heat lost from the house through the basement ceiling, how is this taken into account by the model. After all, when DOE-2 computed the loads, it didn't know how much heat would be lost from the ducts.

This problem is addressed in the following way. The model is run for an entire heating or cooling season with the hourly loads as calculated by DOE-2, assuming that there is no impact of the duct system on the building. (This in effect assumes that the ductwork is not thermally connected to the conditioned space except through the registers.) The heat losses from the ducts to the buffer zone in which they are located is computed by DUCTSIM. These losses are then input to DOE-2 during a second run (over the same entire heating or cooling season), in which their effect on the building is taken into account. The impact on the load affects 
the required run time of the heating or cooling system, and hence the duct losses will change. These losses are input to DOE-2 during a third iteration (again another run over the entire season), which is generally enough to give adequate convergence, but if not a fourth iteration can be run.

The intended interaction of the hydronic submodel with the LBL model is shown in Figure 2. The LBL model is run in a mode in which DUCTSIM is deactivated and COMIS computes only in-zone air flows, not those in the ducts (because there are no ducts). For each hour simulated, the hydronic submodel accepts the load computed by DOE-2 and computes the energy flows through the boiler and distribution system needed to meet this load. It also computes the heat lost to spaces other than the conditioned space. Thus, it plays a role analogous to DUCTSIM in the basic LBL model.

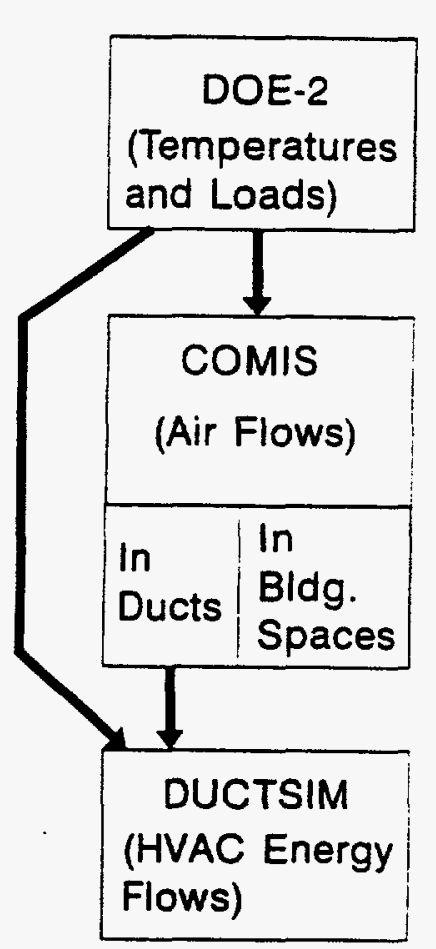

Figure 1. Schematic representation of the LBL thermal distribution model.

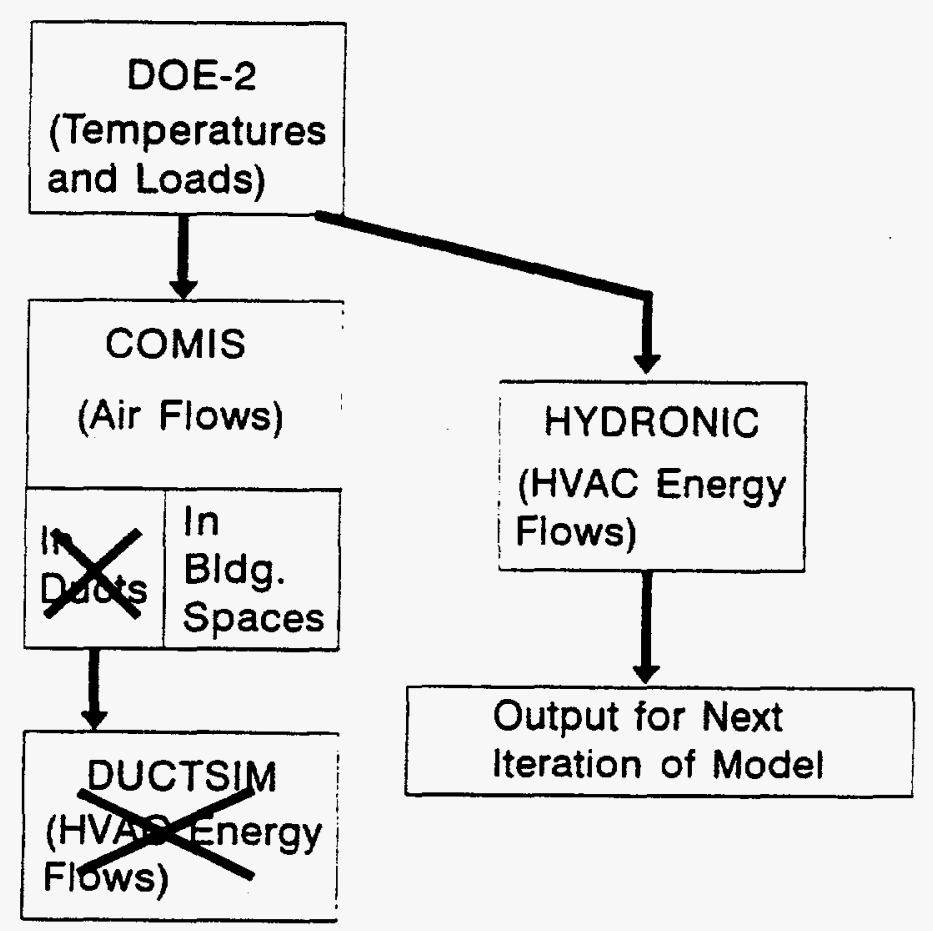

Figure 2. Intended interaction of the hydronic submodel with the LBL model. 


\section{APPROACH TO HYDRONIC SYSTEM MODELING}

The approach we have taken was to write a HYDRONIC program that would substitute for DUCTSIM in the LBL model. HYDRONIC has as inputs a set of fixed parameters that define the boiler and the distribution system, which in this first version is conceptualized specifically as a baseboard hot-water loop. other types of hydronic systems, such as radiant systems, steam systems, and systems that employ fan-coil units, may be added later.

The fixed parameters include boiler input rate, stack and jacket loss rates in both the on-cycle and off-cycle, boiler thermal mass, circulator flow rate, and hydronic-system physical parameters such as pipe diameter, pipe-system layout and dimensions (by building zone), and effective heat-transfer coefficient (UA) to each zone.

In addition to the fixed parameters, HYDRONIC will depend on the LBL model in which it is embedded to provide it, on an hourly basis, with the zone temperatures, the outside ambient temperature, and the space heating load it is required to meet for each given hour.

The program will use the load from DOE-2 and the current zone temperatures as inputs. It will operate the hydronic system so as to meet the load and therefore maintain the setpoint temperature of the conditioned space. Its outputs will consist of heat deposited (intentionally or unintentionally) in each zone, including the buffer zone that contains whatever piping is not in the conditioned space.

A boiler model has been included in the package, so that the overall energy use, stack and jacket losses, as well as piping losses can be handled. This model is a relatively simple one that fit the data well in a study done in the mid-1980's on low-firingrate systems. 


\section{MODEL DESCRIPTION}

The model is predicated on a boiler and a hydronic loop. The loop is split into sections of pipe, each having the same fluid storage capacity (Figure 3). The requirement that each section have the same fluid storage capacity was set so that during each timestep the fluid in one section will move entirely to the next section. This was done to make it easier to program the operation of the loop. It should not prove to be an undue limitation, since the loop can be divided into as many sections as needed. For example, a typical hydronic loop is about $150 \mathrm{ft}$ long. If this is divided into 6-foot sections, a total of 25 sections would be required. This should permit reasonable accuracy for most situations. The program is fast enough that more sections can be used if this is seen to be desirable.

The main subroutine of the model, named HYDRO, is flowcharted in Figure 4. In order to operate, this program needs three sets of inputs. The first is the parameter set that describes the hydronic system. These parameters are as follows:

1. Zone in which boiler is located (conditioned or buffer space)

2. Boiler thermal mass

3. Upper and lower limits on boiler-water temperature

4. Boiler firing rate

5. Stack efficiency of the boiler in steady-state operation

6. Jacket-loss heat transfer coefficient (UA)

7. Off-cycle stack-loss heat transfer coefficient (UA)

8. Maximum circulator cycles per hour (at $50 \%$ ontime)

9. Number of pipe sections

10. Water flow rate in pipe

11. Internal volume of a pipe section

12. For each pipe section:

12A. Zone in which section is located

12B. Heat-transfer coefficient (UA) to the zone

12C. Heat-transfer coefficient (UA) to the exterior

12D. Thermal mass of the pipe material (including fins if any)

The second set of inputs is the ones provided to the hydronic model by the LBL model. These are as calculated by DOE-2 in that model. These inputs are:

1. Heating load for the hour

2. Temperature in the conditioned space

3. Temperature in the buffer space

4. Outdoor ambient temperature

The third set of inputs is generated by the hydronic model itself in a preliminary run that is done on the first hour's call from the LBL model. This consists of a table that defines the circulator fractional ontime and number of cycles per hour as functions of the hourly heating load. This table is generated by 
a subprogram called LOADCURVE. We now describe the operation of HYDRO, the principal subroutine of the hydronic model, assuming that this table has been generated. The theory and operation of LOADCURVE is described following this.

HYDRO begins by calling on LOADCURVE to generate the table described above. Following this, for each hour of the simulation, HYDRO uses this table to decide what circulator fractional ontime and number of cycles per hour it will use. For example, if the fractional ontime is 0.2 and 4 cycles per hour are called for, then that hour's simulation will have the circulator on for 3 minutes and off for 12 minutes for four successive 15-minute cycles within that hour.

The program then runs through a loop in which the time moves through the 3600 seconds of the hour, with a timestep DTHX equal to the number of seconds required for a particle of water to pass from the beginning of one pipe section to the beginning of the next. within each step of the loop, the program first determines whether the circulator is on. If it is, it first shifts the water in the pipe forward one section. It then calculates the heat transfer from the water to the pipe and then from the pipe to the surroundings, using the log-mean temperature difference approach. starting with a given inlet temperature to a pipe section, the outlet temperature that gives consistency between heat transfer from the section and heat lost by the thermal mass of the section is used as the "flow heat transfer."

If the circulator is off, the program allows the water in the pipe section to relax in temperature as a single mass losing heat to the outside with a time constant equal to the thermal mass of the section divided by the UA value. This is called the "relaxation heat transfer."

The next step is to calculate the boiler heat flows. The details of the boiler model are given below, following the description of LOADCURVE. This model decides whether the burner is off or on and then computes the heat flows into and out of the boiler from/to the burner, the stack, the jacket, and the hydronic loop.

The next step is to decide whether the heating load will be met if the circulator is shut down at this point. This step is necessary because heat continues to flow into the conditioned space even after circulator shutdown, because of stored heat in the pipes. Because the LBL model is load-driven and not thermostatdriven, the submodel must ensure that it meets the given load as nearly as possible. Thus, a calculation is made of the heat that would be delivered to the conditioned space by the end of the hour, under the assumption that the circulator is shut down for the rest of the hour, overriding any previous decision concerning fractional 
ontime. If the answer is that the heat would be insufficient to meet the load, control of the circulator remains with HYDRO according to the schedule established at the beginning of the hour. If the answer is that enough heat would be delivered with no further operation of the circulator, then the circulator is shut down and the tentative calculation of heat transfer to the end of the hour is made permanent and the clock is advanced to the end of the hour also.

When the end of the hour is reached, the program passes on to the next hour. In general, we find that agreement between the heat given up to the conditioned space and the heating load is not exact. Usually the difference is less than $100 \mathrm{Btu}$. In any case, a modification to the program that will carry over any difference to the next hour needs to be made to avoid cumulative discrepancies. That is, if in any hour the system provided somewhat more heat than called for, then in the next hour it needs to provide a little less. This is an easy change to make and will be done early in the next phase of the project.

For each hour of operation, HYDRO outputs all the relevant energy flows involving the boiler or the hydronic loop. These include fuel used, stack losses, jacket losses, heat delivered to the hydronic loop, heat given up from the hydronic system to the conditioned space, heat from hydronic to buffer space, and heat from hydronic directly to the outside (if any). Also, the boilerwater temperature and temperatures in the pipe loop are recorded, allowing a determination of net heat storage in the boiler and the loop.

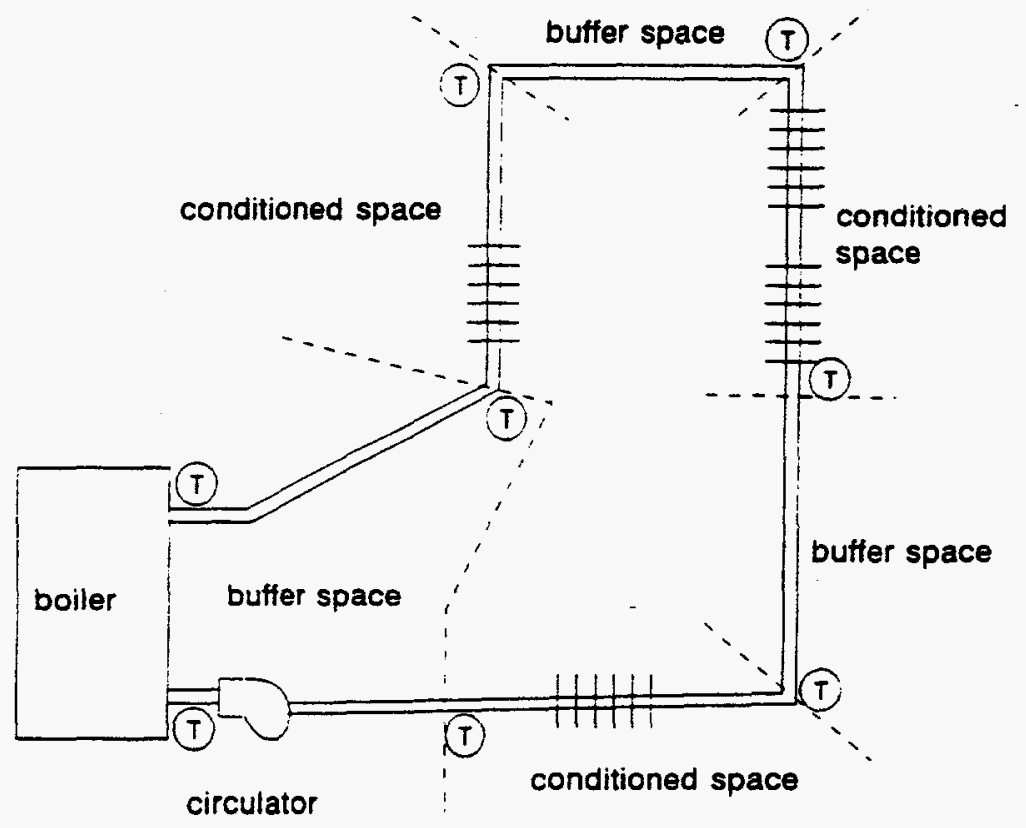

Figure 3. Hydronic Loop Divided into Sections 


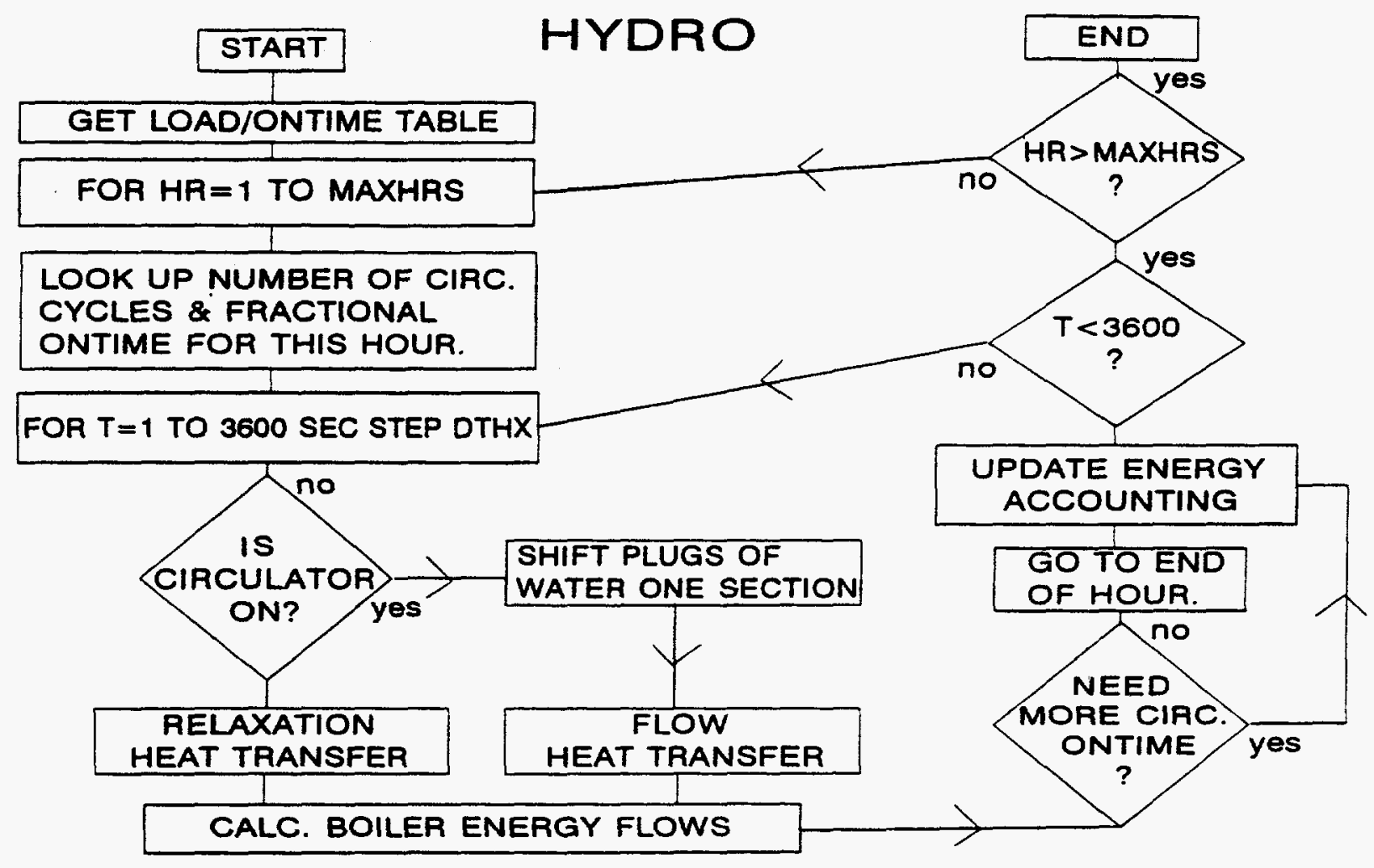

Figure 4. HYDRO Program Flow Chart



Figure 5. LOADCURVE Program Flow Chart 


\section{Subprogram LOADCURVE}

As mentioned above, HYDRO's first job, which it performs once on the first call from the main program (the LBL model), is to establish a baseline relationship between the heating load and the number and duration of circulator on-periods for that hour. This is performed by a subroutine called LOADCURVE. The objective is to force HYDRO to operate as nearly as possible within the standard parabolic relationship of cycles per hour versus fractional ontime:

$$
\mathrm{N}=4 \mathrm{~N}_{\max } f(1-f)
$$

where $\mathbf{N}$ is the number of cycles per hour, $\mathbf{N}_{\max }$ is the maximum number of cycles per hour, and $f$ is the fractional ontime of the circulator. This relationship ensures that $N=N_{\max }$ when $f=0.5$ and that $N$ drops off toward zero as $f$ approaches zero or one. In the real world, $N$ need not be an integer, but in the simulation we will have to use integral values of $\mathrm{N}$ since the simulation goes in onehour timesteps.

The derivation of this formula, which is a standard assumption in much modeling work (and which was verified in the ASHRAE SP-43 project [Jakob et al. 1987] for forced-air systems), follows from some simple assumptions that should hold at least approximately:

- The rate at which heat is delivered to the building when the circulator is on is approximately constant (with value $Q_{\text {in }}$ $\mathrm{Btu} / \mathrm{h})$. The rate at which heat is delivered to the building when the circulator is off can be ignored.

- The rate of heat loss from the building is constant (with value $\left.Q_{\text {out }} B t u / h\right)$.

- The thermal mass of the house is a constant (htmass, Btu/F).

- The thermostat deadband is constant (with value $\Delta \mathrm{T}$ in ${ }^{\circ} \mathrm{F}$ ).

Given these assumptions, the on-period of the circulator is given by the time needed to warm the building through the thermostat deadband:

$$
t_{\mathrm{on}}=\text { htmass } \Delta \mathrm{T} /\left(\mathrm{Q}_{\mathrm{in}}-\mathrm{Q}_{\mathrm{out}}\right)
$$

while the off-period is the time needed for the building to cool down through the same thermostat deadband:

$$
t_{\text {off }}=\text { htmass } \Delta \mathrm{T} / Q_{\text {out }}
$$

The sum of these two quantities is then

$$
t_{\text {on }}+t_{\text {off }}=\text { htmass } \Delta \mathrm{T} Q_{\text {in }} /\left[Q_{\text {out }}\left(Q_{\text {in }}-Q_{\text {out }}\right)\right]
$$


But this is just the time for one complete cycle, so the number of cycles per hour is the inverse of this quantity

$$
N=\left(t_{\text {on }}+t_{\text {off }}\right)^{-1}=\left[Q_{\text {out }}\left(Q_{\text {in }}-Q_{\text {out }}\right)\right] /\left(\text { htmass } \Delta T Q_{\text {in }}\right)
$$

The fractional ontime is defined as the ratio of on-period to total on-plus off-period

$$
f_{\text {ontime }}=t_{o n} /\left(t_{o n}+t_{o f f}\right)
$$

and using equations 2 and 4 , this can be reduced to

$$
f_{\text {ontime }}=Q_{\text {out }} / Q_{\text {in }}
$$

Equation 5 is now rearranged slightly to

$$
\begin{aligned}
N & =\left(Q_{\text {out }} / Q_{\text {in }}\right)\left[1-\left(Q_{\text {out }} / Q_{\text {in }}\right)\right] Q_{\text {in }} /(\text { htmass } \Delta T) \\
& =f_{\text {ontine }}\left(1-f_{\text {ontime }}\right) Q_{\text {in }} /(\text { htmass } \Delta T)
\end{aligned}
$$

This is seen to have the parabolic dependence referred to above.

An initializing program called LOADCURVE (Figure 5) generates a table of loads and fractional ontimes leading to all possible integer values of $\mathrm{N}$. This is done, first, by solving Equation 1 for $f$ as a function of $N$ and then getting the circulator ontime $t_{o n}=f / N$ and offtime $t_{o f r}=(1-f) / N$. These values are then run through the same algorithm as the main program HYDRO (see above) for one hour, with the boiler-water temperature and the temperature in the pipes beginning at a preset value, and with the boiler-water temperature (but not the pipe temperatures) held constant for the rest of the hour.

A hypothetical example of such a table is given below:

$\begin{array}{ccc}\begin{array}{l}\text { Load Met } \\ \text { (kWh) }\end{array} & \begin{array}{l}\text { Cycles } \\ \text { per hour }\end{array} & \begin{array}{l}\text { Fractio } \\ \text { ontime }\end{array} \\ 0 & 0 & 0 \\ 0.7 & 1 & 0.044 \\ 1.4 & 2 & 0.092 \\ 2.2 & 3 & 0.146 \\ 3.1 & 4 & 0.211 \\ 4.2 & 5 & 0.296 \\ 6.4 & 6 & 0.500 \\ 8.2 & 5 & 0.704 \\ 8.8 & 4 & 0.789 \\ 9.2 & 3 & 0.853 \\ 9.5 & 2 & 0.908 \\ 9.8 & 1 & 0.956 \\ 10.0 & \text { continuous } & 1.000\end{array}$


Note that while the cycles-per-hour curve will be symmetric about the 0.5 fractional on-time point, the load met at 50 s ontime will be more than 50\% of the load met at full ontime, because the thermal mass of the water will still be releasing heat even when the circulator is off.

One other small task is to compute dthx, the time for a given elemental volume of water to be pumped from the beginning to the end of a pipe section. This is just the volume of the section divided by the pumping rate of the circular.

\section{Boiler Model}

The boiler model is relatively simple. It is based on the idea that, when the boiler is on, it operates at steady-state efficiency, with stack and jacket losses dependent on boiler water temperature (BWT), and when it is off it delivers no heat but incurs stack and jacket losses that are (possibly different) functions of BWT. Such a model fit the data well in earlier BNL work. [Andrews 1985] This approach to modeling the boiler is summarized as follows:

Boiler section (Circulator oN)

1. Remove boiler water for first section of loop a beginning boiler-water temperature (BWT) and replace with water from last pipe section at whatever temperature it is now at.

2. Recompute BWT.

3. Decide whether the boiler is oN or ofF for this section's time slot.

If OFF, leave it OFF unless $B W T<T_{\min }$

If $O N$, leave it oN unless $B W T>T_{\max }$

$\left(T_{\min }\right.$ and $T_{\max }$ are the minimum and maximum allowed boiler-water temperatures. Typical values would be $\mathrm{T}_{\min }=150 \mathrm{~F}(65 \mathrm{C})$ and $\mathrm{T}_{\max }=180 \mathrm{~F}(85 \mathrm{C})$.

If boiler is now OFF: Remove stack-loss heat. Remove jacket-loss heat. Dump jacket-loss heat to zone the boiler is in.

If boiler is now on:

Add heat to boiler water e stack efficiency.

Remove jacket-loss heat. Dump jacket-loss heat to zone the boiler is in.

4. Recompute BWT at end of this section's time slot. 
Boiler Section (Circulator OFF)

1. If boiler was oN at beginning of the circulator-off period, calculate how long to leave it on so that BWT hits $T_{\max }$ (maximum time: to end of circulator-off period).

IF boiler was OFF at beginning of circulator-off period, leave it off. (BWT might go a degree or two below $\mathbf{T}_{\min }$ )

2. Compute jacket, stack losses and BWT at end of circulator-off period.

\section{Energy Accounting}

The program keeps track of all energy flows in the boilerhydronic subsystem. This includes fuel use, heat delivered to the heated space, heat lost to the buffer space, stack losses, and jacket losses. Temperatures within the boiler and all parts of the hydronic loop are also tracked. The program does its best to exactly meet the load presented to it by DOE-2; however, small discrepancies are expected because the number of pipe sections through which water is pumped during any timestep must be an integer. Any such discrepancy is added to or subtracted from the next timestep's load.

\section{Multiple Zones}

DOE-2 requires that the building equipment exactly meet the calculated load for the hour. In the event that there is more than one heated zone, three possibilities present themselves. One is that each zone is served by a separate loop with its own circulator. This could easily be handled by modifying the program to keep track of two or more loops simultaneously. The second possibility is that a single circulator is used with a zone valve. This might be handled by substituting a multiple circulator arrangement and letting it meet the loads, or it might require additional program development. The third possibility is that a single loop with a single circulator serves both zones. In this case, it will generally not be possible to satisfy both (or all) loads simultaneously. This is true in the real world as well as in the model. To handle such a situation it will be necessary to modify DOE-2. None of the modifications necessary to handle multiple zones was included in the scope of the current project.

\section{Algorithms and computer code}

A description of certain algorithms developed for the model is given in Appendix 1. The code for the program, as of october 5, 1994, is given in Appendix 2. 


\section{RESULTS OF PRELIMINARY RUNS}

Boiler and Circulator cycling

Several runs were made to look at the cycling behavior of the boiler in conjunction with that of the circulator. In general, it was found that if a constant circulator cycling rate and fractional ontime are forced onto the system, that the boiler very quickly falls into step with the circulator, though not necessarily with the same number of cycles per hour. That is, the boiler cycles at a rate that involves an integral number of boiler on-cycles during a time period that also contains an integral number of circulator on-cycles. This type of behavior is expected for a system driven by a periodic input, and therefore lends some confidence that the coupling between the circulator and the boiler in the model is proceeding in a reasonable fashion.

Figures 6 and 7 show the progression of the boiler-water temperature and the average water temperature in three pipe sections over a one-hour period. The distribution system had 12 pipe sections. Section 2 was in the conditioned space, with a high heat-exchange UA representing finned baseboard. Section 6, near the middle of the loop, was in the basement and had no fins. In Figure 6 , this pipe was uninsulated, with a UA of 6 Btu/h-F for a 15-foot section. In Figure 7, the pipe was insulated to approximately an $\mathrm{R}-3$ value, with the overall UA reduced to $1 \mathrm{Btu} / \mathrm{h}-$ $F$ for the same 15-foot section. Section 11 was similar to section 2 , but was located near the end of the loop.

As can be seen from the figures, the boiler comes on every other time the circulator comes on. This behavior is dependent on the characteristics of the boiler, in particular of its thermal mass. In this run, the circulator came on for three minutes out of 15 minutes ( $20 \%$ ontime). The thermal mass of the boiler was enough to get it through one circulator on-cycle without needing to fire; the next circulator-on cycle then drew the boiler-water temperature down sufficiently to incite the burner.

The temperatures in the pipes are seen to follow what generally would be expected: earlier sections have higher water temperatures than later ones when the circulator is on. When the circulator is off, the temperatures in the pipes relax in accordance with their heat-exchange UA values. Thus, the insulated pipe section in the basement (Figure.6) relaxes more slowly than the uninsulated one (Figure 7).

\section{Energy Balances}

Energy balances on boiler and circulating loop were taken for the several cases. Each case represents a run in which the boiler and hydronic loop end in the same state at which they started. 


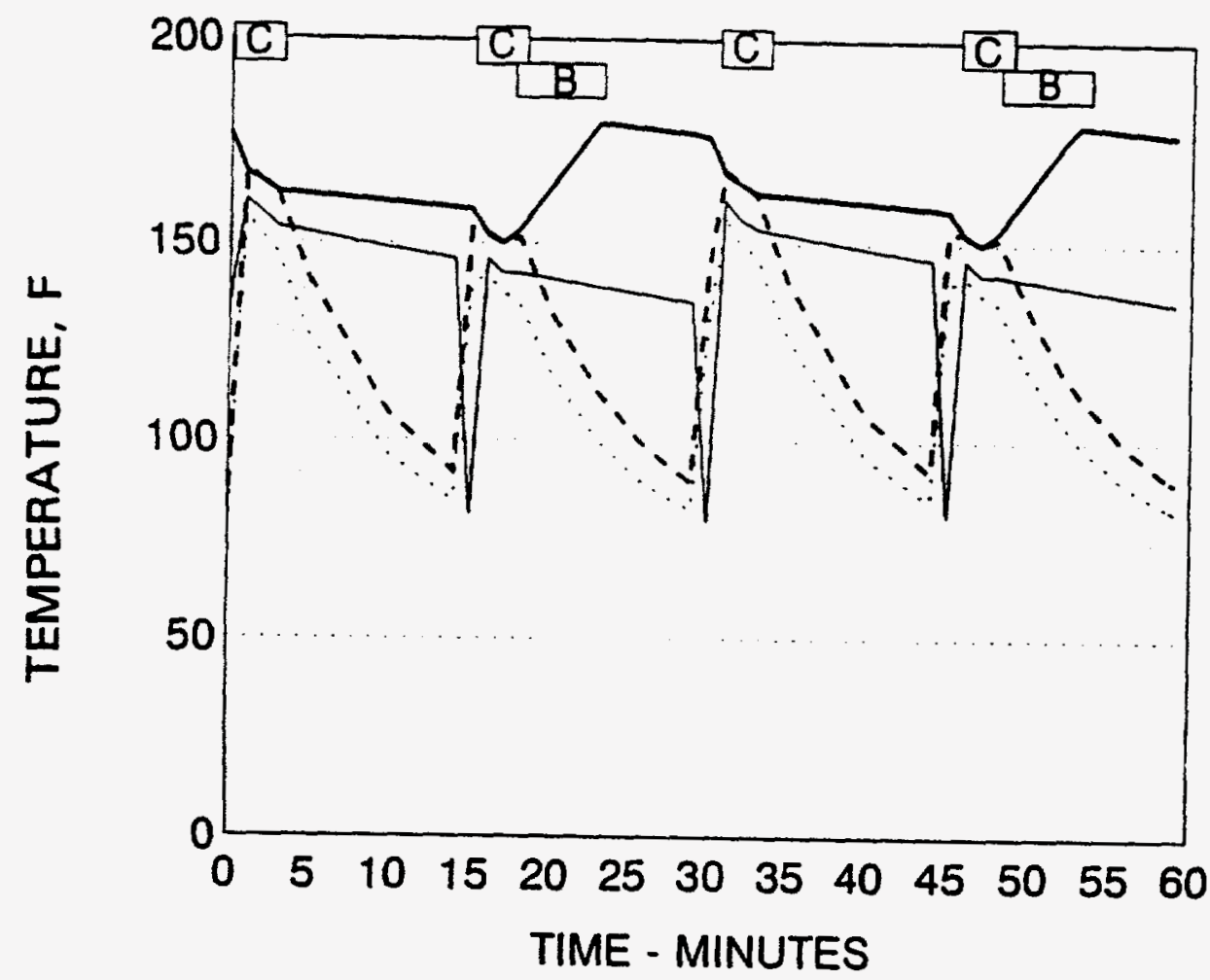

- Boiler

- - Section 2

- Section 6

Section 11

Figure 6. Boiler water and pipe temperatures, insulated pipe.

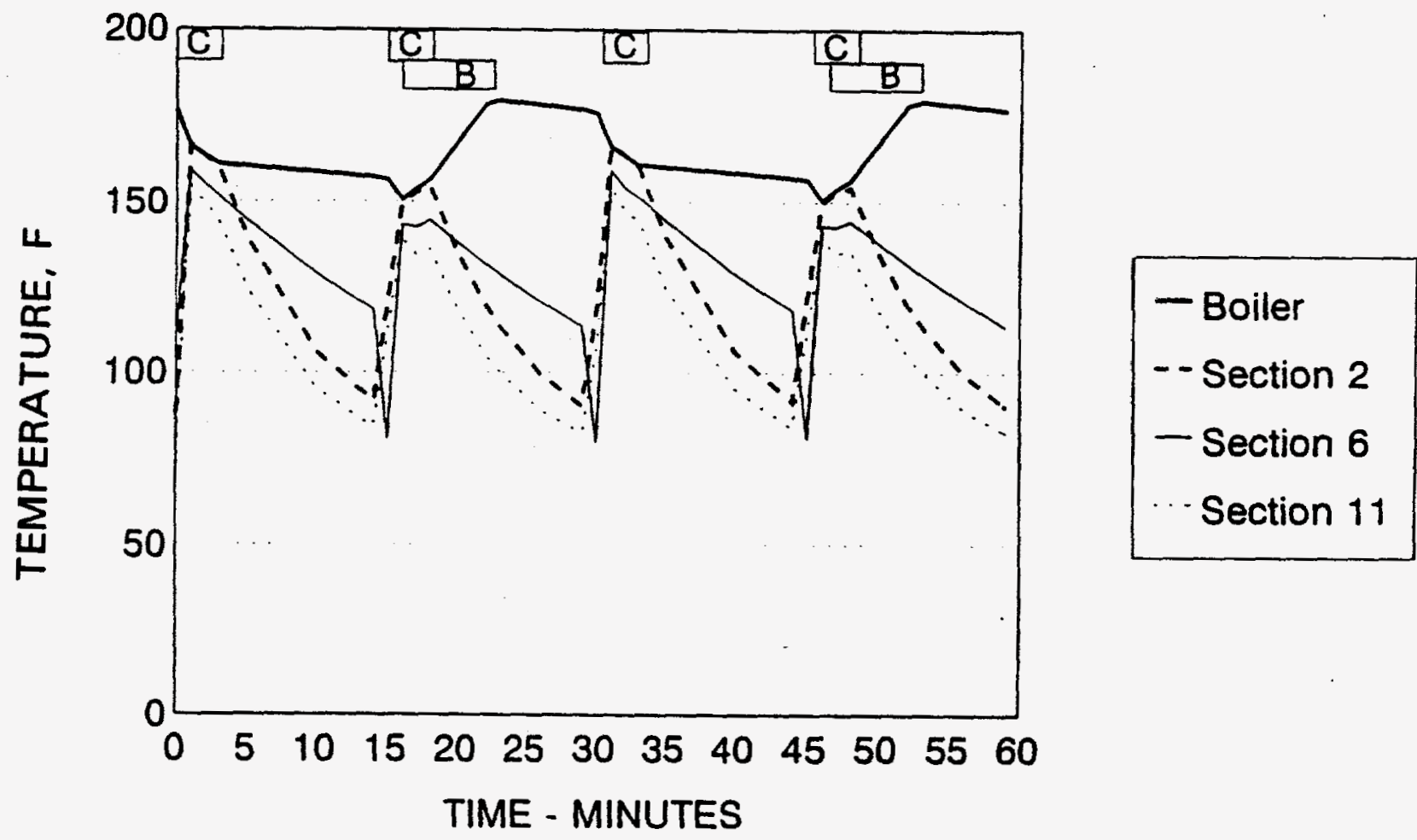

Figure 7. Boiler water and pipe temperatures, uninsulated pipe. 
Table 1 shows the results of these runs. Energy balances on both the boiler and the hydronic loop showed closure. In several respects the behavior of the system was as expected. Equipment efficiency declines with decreasing boiler fractional ontime. For a given circulator fractional ontime, slightly more heat is delivered to the hydronic loop when the pipes are uninsulated; this is due to the fact that the return water is cooler under that condition. Insulating the pipe improves the delivery efficiency of the hydronic loop, but it degrades the equipment efficiency slightly because of the lower boiler fractional ontime.

An additional run was done with all the pipe sections in the conditioned space and all having identical UA values. This was done to check whether the heat transfer from the pipe to the zone was reasonable. In this case, the heat delivered per hour to the conditioned space by the 12 pipe sections was calculated, using a one-minute slice of time after the system had reached steady state. The results were as follows:

1. The heat stated by the program as delivered to the zone was 805.32 Btu for the minute, or $48,319 \mathrm{Btu} / \mathrm{h}$.

2. A calculation based on the temperature difference between the entering and leaving water was as follows:

Flow rate: $24 \mathrm{ft}^{3} / \mathrm{h}$

Volume specific heat of water: $62.4 \mathrm{Btu} / \mathrm{ft}^{3}-\mathrm{F}$

Temperature of water entering loop from boiler: $167.78 \mathrm{~F}$

Temperature of water returning to boiler from loop: $135.56 \mathrm{~F}$

Delivered heat $=24 \times 62.4 \times(167.78-135.56)=48253 \mathrm{Btu} / \mathrm{h}$

3. A calculation of the expected heat transfer using the overall UA and the log-mean temperature difference between the water and the conditioned space:

Overall UA $=50 \mathrm{Btu} / \mathrm{h}-\mathrm{F}$ per section, or $600 \mathrm{Btu} / \mathrm{h}-\mathrm{F}$ for all 12 sections

$\Delta \mathrm{T}_{\max }=167.78-70.0=97.78 \mathrm{~F}$

$\Delta \mathrm{T}_{\min }=135.56-70.0=65.56 \mathrm{~F}$

$$
\Delta T_{\text {log-mean }}=\frac{97.78-65.56}{\ln \left(\frac{97.78}{65.56}\right)}=80.60
$$

Delivered heat $=600 \times 80.60=48360 \mathrm{Btu} / \mathrm{h}$

These three values are within 0.3 percent of one another. 
Table 1. Energy Balances on Six Cases. Energies in Btu/h.

\begin{tabular}{|c|c|c|c|c|c|c|}
\hline Case & A. 1 & B. 1 & C. 1 & A. 6 & B. 6 & C. 6 \\
\hline $\begin{array}{l}\text { Circulator } \\
\text { Fractional } \\
\text { ontime }\end{array}$ & 0.5 & 0.2 & 0.1 & 0.5 & 0.2 & 0.1 \\
\hline $\begin{array}{l}\text { Circulator } \\
\text { Cycles/Hour }\end{array}$ & 6 & 4 & 2 & 6 & 4 & 2 \\
\hline $\begin{array}{l}\text { Pipes in } \\
\text { Basement } \\
\text { Insulated? }\end{array}$ & Yes & Yes & Yes & No & No & No \\
\hline Fuel Used & 25,420 & 15,546 & 10,798 & 27,727 & 17,372 & 11,855 \\
\hline Stack Loss & 5,282 & 4,123 & 3,489 & 5,569 & 4,345 & 3,621 \\
\hline Jacket Loss & 2,158 & 2,215 & 2,163 & 2,157 & 2,209 & 2,161 \\
\hline $\begin{array}{l}\text { Heat to } \\
\text { Hydronic Loop }\end{array}$ & 17,979 & 9,208 & 5,147 & 20,000 & 10,818 & 6,073 \\
\hline $\begin{array}{l}\text { Boiler } \\
\text { Residual }\end{array}$ & 1 & 0 & 1 & 1 & 0 & 0 \\
\hline $\begin{array}{l}\text { Boiler } \\
\text { Fractional } \\
\text { Ontime }\end{array}$ & 0.318 & 0.194 & 0.135 & 0.347 & 0.217 & 0.148 \\
\hline $\begin{array}{l}\text { Heat to Cond- } \\
\text { itioned space }\end{array}$ & 17,560 & 8,750 & 4,675 & 17,247 & 8,518 & 4,337 \\
\hline $\begin{array}{l}\text { Heat to } \\
\text { Basement }\end{array}$ & 419 & 458 & 472 & 2,753 & 2,300 & 1,736 \\
\hline $\begin{array}{l}\text { Hydronic Loop } \\
\text { Residual }\end{array}$ & 0 & 0 & 0 & 0 & 0 & 0 \\
\hline Delivery Eff. & 0.977 & 0.950 & 0.908 & 0.862 & 0.787 & 0.714 \\
\hline Equipm't Eff. & 0.707 & 0.592 & 0.477 & 0.721 & 0.623 & 0.512 \\
\hline
\end{tabular}


The next step was to bring the program to the point where it included the "front end" in HYDRONIC, where it computes the table of loads vs. fractional on-times. Given a maximum number of circulator on-cycles per hour (which is related to the thermostat deadband and the thermal mass of the house, as described above) the program generates a table of fractional on-times and cycles-perhour as functions of hourly heat loads. For each hour of actual running, the program interpolates in this table to pick out a circulator fractional ontime and number of circulator cycles per hour that would deliver this amount of heat.

This program was exercised for two 24-hour runs, one assuming the pipes in the unconditioned space to be uninsulated, the other assuming them to be insulated at approximately R-3 (English units). The 24 heating load values were selected to approximate a moderately cold winter day in which significant solar gain occurred during the daytime, reducing the minimum hourly demand to less than one-third the maximum. The actual loads used were:

$\begin{array}{lllr}\begin{array}{l}\text { Time at start } \\ \text { of hour }\end{array} & \begin{array}{l}\text { Heat Load } \\ \text { (Btu) }\end{array} & \begin{array}{l}\text { Time at start } \\ \text { of hour }\end{array} & \begin{array}{c}\text { Heat Loa } \\ \text { (Btu) }\end{array} \\ 0000 & 20,000 & 1200 & 7,000 \\ 0100 & 21,000 & 1300 & 7,000 \\ 0200 & 22,000 & 1400 & 8,000 \\ 0300 & 23,000 & 1500 & 10,000 \\ 0400 & 24,000 & 1600 & 12,000 \\ 0500 & 25,000 & 1700 & 13,000 \\ 0600 & 24,000 & 1800 & 14,000 \\ 0700 & 22,000 & 1900 & 15,000 \\ 0800 & 19,000 & 2000 & 16,000 \\ 0900 & 16,000 & 2100 & 17,000 \\ 1000 & 12,000 & 2200 & 18,000 \\ 1100 & 9,000 & 2300 & 19,000\end{array}$

other information relevant to these runs is as follows:

$\begin{array}{ll}\text { Temperature in living space: } & 70 \mathrm{~F} \\ \text { Temperature in basement: } & 50 \mathrm{~F} \\ \text { Boiler Location: } & \text { Basement } \\ \text { Boiler Thermal Mass: } & 200 \mathrm{Btu} / \mathrm{F} \\ \text { Boiler Water Temperature Bounds: } & 150 \mathrm{~F}-180 \mathrm{~F} \\ \text { Firing Rate: } & 80000 \mathrm{Btu} / \mathrm{h} \\ \text { Stack Efficiency: } & 0.85 \\ \text { Jacket Heat-Loss Coeff. (UA): } & 20 \mathrm{Btu} / \mathrm{F}-\mathrm{h} \\ \text { Off-Cycle Stack-Loss Coeff. (UA): } & 20 \mathrm{Btu} / \mathrm{F}-\mathrm{h} \\ \text { Maximum Circulator Cycles per Hour: } & 6 \\ \text { Number of Pipe Sections } & 12 \\ \text { Water Flowrate: } & 2.88 \mathrm{gallons} \text { per minute } \\ \text { Thermal Mass Water/15-ft Pipe section } & 2.08 \mathrm{Btu} / \mathrm{F}\end{array}$


The section-specific thermal characteristics of the hydronic loop are as follows:

$\begin{array}{llll}\text { Section } & \begin{array}{l}\text { Location } \\ \text { UA } \\ \text { (Btu/F-h) }\end{array} & \begin{array}{l}\text { Pipe } \\ \text { Mass }\end{array} & \begin{array}{l}\text { Thermal } \\ \text { (Btu/F) }\end{array} \\ 1 & \text { Basement } & 1 \text { or } 6 & 0.7 \\ 2 & \text { Living Space } & 50 & 1.0 \\ 3 & \text { Basement } & 1 \text { or } 6 & 0.7 \\ 4 & \text { Living Space } & 90 & 1.4 \\ 5 & \text { Living Space } & 90 & 1.4 \\ 6 & \text { Basement } & 1 \text { or } 6 & 0.7 \\ 7 & \text { Living Space } & 70 & 1.2 \\ 8 & \text { Basement } & 1 \text { or } 6 & 0.7 \\ 9 & \text { Living Space } & 100 & 1.5 \\ 10 & \text { Basement } & 1 \text { or } 6 & 0.7 \\ 11 & \text { Living Space } & 100 & 1.5 \\ 12 & \text { Basement } & 1 \text { or } 6 & 0.7\end{array}$

Note: UA for sections in basement is $1 \mathrm{Btu} / \mathrm{F}-\mathrm{h}$ if pipe is insulated and $6 \mathrm{Btu} / \mathrm{F}-\mathrm{h}$ if pipe is uninsulated.

\section{Energy Balances}

A check of the energy balances on the boiler and the distribution system for the day's runs was made. For the boiler, the fuel input should equal the sum of stack losses, jacket losses, heat delivered to the distribution system, and net heat stored in the boiler (due to any boiler-water temperature increase or decrease between the beginning and end of the day). For the distribution system, the heat delivered by the boiler should equal the heat given up to the conditioned space, the heat lost to the basement, and net heat stored in the pipes (due to any temperature increase or decrease in the hydronic loop between the beginning and end of the day). These balances are shown in Table 2 .

The striking things to note here are the small residuals on the energy balances and the dramatic increase in hydronic system delivery efficiency gained by insulating the pipes. Figure 8 shows a breakdown of the delivery efficiency as a function of hourly heating load. The "droop" in the uninsulated-pipe efficiencies with decreasing heating loads is reminiscent of a boiler efficiency curve. The raggedness of the insulated-pipe values is in part due to the fact that the hourly values were not corrected for changes in heat stored in the pipes.

Another thing to note is that the boiler efficiency decreases slightly when the hydronic delivery efficiency increases. This is in line with expectation, due to the greater cycling of the boiler when the need for heat is reduced. The effect is small (a 2.5\% decrease in boiler efficiency accompanying a $12.5 \%$ increase in hydronic delivery efficiency) but it is not negligible. It is to 
be noted that the boiler modeled here is a fairly inefficient model, and that better boilers would suffer smaller losses in efficiency than this.

Table 2. Energy Balances on Boiler and Thermal Distribution System. All Energy Values in Btu Over a 1-Day Period.

\begin{tabular}{|c|c|c|}
\hline & $\begin{array}{l}\text { Pipes in Base- } \\
\text { ment Uninsulated }\end{array}$ & $\begin{array}{l}\text { Pipes in Base- } \\
\text { ment Insulated }\end{array}$ \\
\hline 1. Fuel Input & 638,022 & 582,873 \\
\hline 2. Stack Loss & 131,918 & 125,528 \\
\hline 3. Jacket Loss & 53,954 & 54,429 \\
\hline 4. stored in Boiler & 2,340 & 2,300 \\
\hline $\begin{array}{l}\text { 5. Delivered to } \\
\text { Distribution system }\end{array}$ & 449,794 & 400,425 \\
\hline 6. To Conditioned Space & 393,675 & 394,523 \\
\hline 7. Loss to Basement & 58,255 & 7,754 \\
\hline $\begin{array}{l}\text { 8. Net Heat stored in } \\
\text { Hydronic System }\end{array}$ & $-2,017$ & $-1,677$ \\
\hline $\begin{array}{l}\text { Boiler Residual } \\
(\# 1-\# 2-\# 3-\# 4-\# 5)\end{array}$ & 16 & 191 \\
\hline $\begin{array}{l}\text { Hydronic Residual } \\
(\# 5-\# 6-\# 7-\# 8)\end{array}$ & -119 & -175 \\
\hline $\begin{array}{l}\text { Boiler Efficiency } \\
{[(\# 5+\# 4) / \# 1]}\end{array}$ & 0.709 & 0.691 \\
\hline $\begin{array}{l}\text { Delivery Efficiency of } \\
\text { the Hydronic System } \\
{[(\# 6+\# 8) / \# 5]}\end{array}$ & 0.871 & 0.981 \\
\hline
\end{tabular}




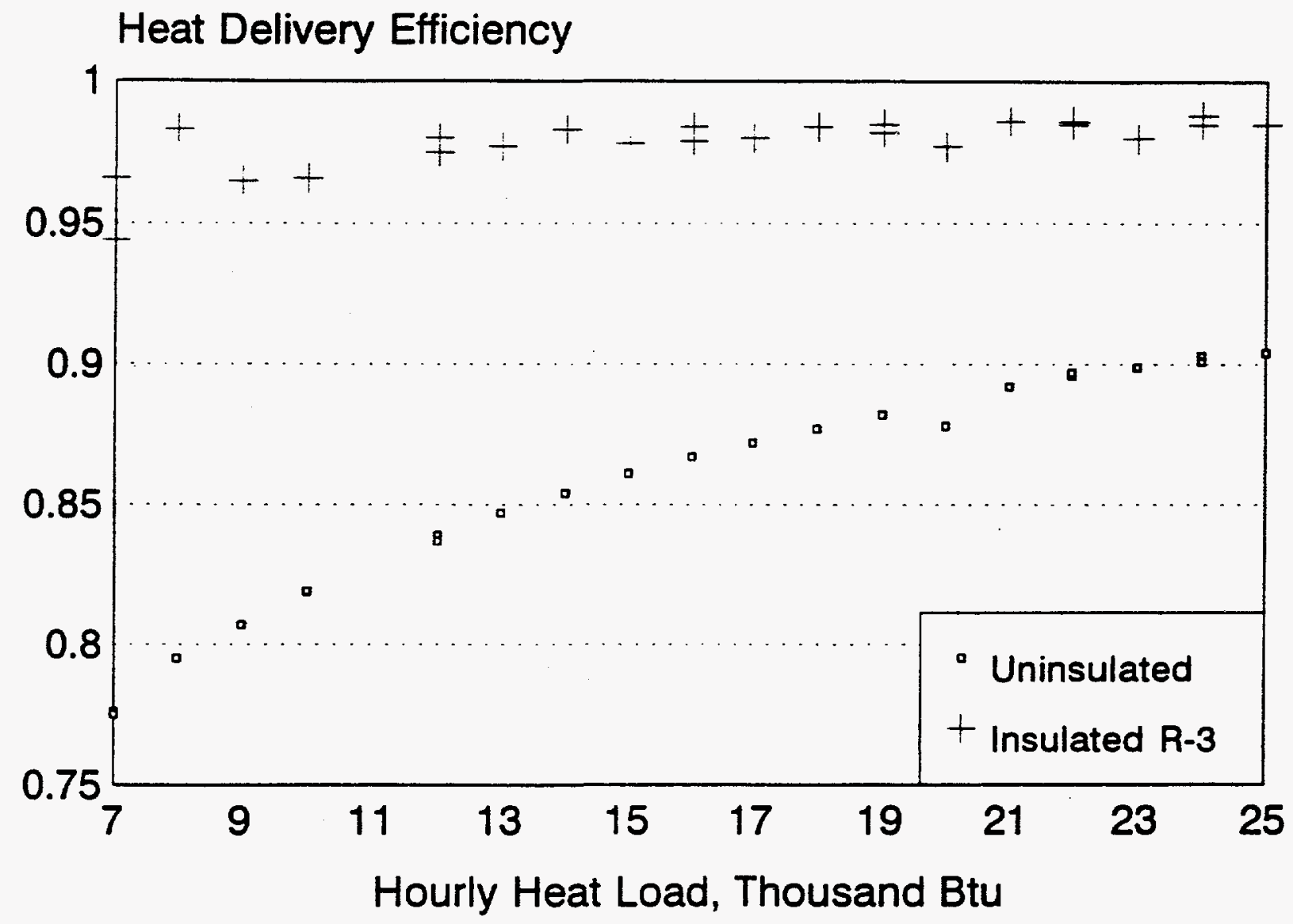

Figure 8. Hydronic Efficiency vs. Heating Load 


\section{RECOMMENDED FUTURE WORK}

The hydronic model is now ready to be exercised over a heating season. A low-cost way to work with the LBL model, without requiring the BNL submodel to be integrated physically with it, would run as follows:

1. Run the LBL model to generate hourly heating loads over a season. Transmit these to BNL on disk.

2. Run the BNL submodel over the season using these heating loads as inputs. Outputs from the BNL model will include hourly values for heat delivered to the conditioned space (which should equal the heating loads) and heat lost to the basement. Transmit to LBL.

3. Run the LBL model again, with the heat losses to the basement as additional inputs that will alter the heating loads computed by DOE-2 (which is an integral part of the LBL model). Transmit these new heating loads to BNL.

4. Rerun the BNL model with the new heating loads. Compare the heat losses to the basement this time with the losses to the basement on the previous run. If convergence is sufficiently close, stop. If not, iterate steps 3 and 4 until convergence is obtained (one more time should be enough).

We are still working on some details of the model. One such item is the fact that the heat-transfer UA is likely to be lower when the water is stagnant than when it is moving, because of the higher film coefficient for moving water. Another is that the capability of modeling direct heat transfer from the pipes to the outside (as would occur due to baseboard units being in contact with an outside wall) has not been exercised. Also, as mentioned in the body of the report, a change to carry over any discrepancy between heating load and delivered heat to the next hour needs to be implemented.

Following sufficient exercise of the model in this fashion, together with validation using real-world data, actual integration of the submodel into the LBL main program would be appropriate. 


\section{APPENDIX 1. ESSENTIAL ALGORITHMS}

In order to model the hydronic system successfully, it was necessary to derive the computational procedures necessary to follow the heat flows in various parts of the system.

\section{Heat Loss from Pipe}

This section derives the equations for the heat loss from a section of hydronic piping, where it is assumed that a heat flow path exists not only to the zone in which the pipe is located, but also an effective heat loss to the outside ambient. This can come about, for example, where pipes run against an outside wall, heating that wall to a warmer temperature than would be the case in the absence of the system. The effective UA for this heat-flow path must be calculated separately; this analysis takes it as an input. We first define the quantities of interest:

\section{Quantity}

$T=$ Temperature of water and pipe

$\mathrm{T}_{\mathrm{a}}=$ Ambient temperature

$\mathrm{T}_{\mathrm{z}}=$ Zone temperature

$h_{\mathrm{a}}=$ Heat-loss coefficient (UA) to ambient

$\mathrm{h}_{\mathrm{z}}=$ Heat-loss coefficient (UA) to zone

$\mathrm{m}_{1}=$ Thermal mass of water and pipe
Units

$\begin{array}{ll}\text { F } & \mathrm{C} \\ \mathrm{F} & \mathrm{C} \\ \mathrm{F} & \mathrm{C} \\ \text { Btu/h-F } & \mathrm{kJ} / \mathrm{h}-\mathrm{C} \\ \text { Btu/h-F } & \mathrm{kJ} / \mathrm{h}-\mathrm{C} \\ \text { Btu/F } & \mathrm{kJ} / \mathrm{C}\end{array}$

1. Solve the basic equation:

$$
\begin{aligned}
\frac{d T}{d t} & =-\frac{h_{z}}{m_{t}}\left(T-T_{z}\right)-\frac{h_{a}}{m_{t}}\left(T-T_{a}\right) \\
& =-\frac{h_{z}+h_{a}}{m_{t}}\left(T-T_{z}\right)-\frac{h_{a}}{m_{t}}\left(T_{z}-T_{a}\right)
\end{aligned}
$$

Let $k=\left(h_{z}+h_{a}\right) / m_{t}, k_{a}=h_{a} / m_{1}, k_{z}=h_{z} / m_{1}$, and $T_{z a}=T_{z}-T_{a}$. Then

$$
\begin{aligned}
\frac{d T}{d t} & =k\left(T-T_{z}\right)-k_{a} T_{z a} \\
& =-k\left(T-T_{z}+\frac{k_{a}}{k} T_{z a}\right)
\end{aligned}
$$

Let $U=T-T_{d}$, where $T_{d}=T_{z}-T_{2 a}\left(k_{a} / k\right)$. Then dU/dt $=\mathrm{dT} / \mathrm{dt}$, and $\mathrm{dU} / \mathrm{dt}=-\mathrm{kU}$. This has the solution $\mathrm{U}=\mathrm{U}_{0} e^{-k t}$, where $U_{0}$ is the value of $U$ at $t$ ime $t=0$.

Substituting the definition of $U$ above, we obtain: 


$$
T=T_{d}+\left(T_{0}-T_{d}\right) e^{-k t}
$$

If we let $x$ equal the final value of time, then

$$
T(x)=T_{d}+\left(T_{0}-T_{d}\right) e^{-k x}
$$

\section{Heat flows:}

Let $\Delta Q_{10}$ equal the total heat loss from the pipe section between the times $t=0$ and $t=x$. Then

$$
\begin{aligned}
\Delta Q_{\text {tot }} & =m_{t}\left(T_{0}-T(x)\right) \\
& =m_{t}\left(T_{0}-T_{d}\right)\left(1-e^{-k x}\right)
\end{aligned}
$$

Let $\dot{Q}_{\mathbf{a}}$ and $\dot{Q}_{z}$ represent the instantaneous heat-loss rates from the pipe section to ambient and to the zone, respectively. Then

$$
\begin{aligned}
\dot{Q}_{a} & =h_{a}\left(T-T_{a}\right) \\
& =m_{t} k_{a}\left[T_{d}-T_{a}+\left(T_{0}-T_{d}\right) e^{-k t}\right]
\end{aligned}
$$

and

$$
\begin{aligned}
\dot{Q}_{z} & =h_{z}\left(T-T_{z}\right) \\
& =m_{t} k_{z}\left[T_{d}-T_{z}+\left(T_{0}-T_{d}\right) e^{-k t}\right]
\end{aligned}
$$

Let $\Delta Q_{\mathrm{a}}$ and $\Delta \mathrm{Q}_{\mathrm{z}}$ equal the heat loss from the pipe section to ambient and to the zone, respectively, between $t=0$ and $t=x$, and note that $\Delta Q_{\mathrm{a}}+\Delta \mathrm{Q}_{\mathrm{z}}$ must equal $\Delta Q_{\text {to }}$. Then:

$$
\begin{aligned}
\Delta Q_{a}=\int_{0}^{X} \dot{Q}_{a} d t & =m_{t} k_{a}\left(T_{d}-T_{a}\right) x+m_{t} k_{a}\left(T_{o}-T_{d}\right) \int_{0}^{X} e^{-k t} d t \\
& =m_{t} k_{a}\left(T_{d}-T_{a}\right) x+\frac{m_{t} k_{a}}{k}\left(T_{0}-T_{d}\right)\left(1-e^{-k x}\right)
\end{aligned}
$$

We check this by adding Equations 8 and 9 , and find: 


$$
\begin{aligned}
\Delta Q_{z}=\int_{0}^{x} \dot{Q}_{z} d t & \left.=m_{t} k_{z}\left(T_{d}-T_{z}\right) x+m_{t} k_{z}\left(T_{0}-T_{d}\right)\right\}_{0}^{x} e^{-k t} d t \\
& =m_{t} k_{z}\left(T_{d}-T_{z}\right) x+\frac{m_{t} k_{z}}{k}\left(T_{0}-T_{d}\right)\left(1-e^{-k x}\right) \\
\Delta Q_{a}+\Delta Q_{z} & =\left[k_{a}\left(T_{d}-T_{d}\right)+k_{z}\left(T_{d}-T_{z}\right)\right] x m_{t}+m_{t} \frac{\left(k_{a}+k_{z}\right)}{k}\left(T_{0}-T_{d}\right)\left(1-e^{-k x}\right) \\
& =\left[k_{a}\left(T_{d}-T_{a}\right)+k_{z}\left(T_{d}-T_{z}\right)\right] x m_{t}+\Delta Q_{t o t}
\end{aligned}
$$

in view of Equation 5 and $k_{a}+k_{2}=k$. The first term to the right of the equal sign in the second line of Equation 10 should therefore equal zero. But using the definition of $T_{d}$ we find:

$$
\begin{aligned}
k_{a}\left(T_{d}-T_{a}\right)+k_{z}\left(T_{d}-T_{z}\right) & =k_{a}\left(1-\frac{k_{a}}{k}\right) T_{z a}-k_{z} \frac{k_{a}}{k} T_{z a} \\
& =k_{a} T_{z a}-\left(k_{a}+k_{z}\right) \frac{k_{a}}{k} T_{z a} \\
& =k_{a} T_{z a}-k_{a} T_{z a} \\
& =0 .
\end{aligned}
$$

\section{Correction Factor}

In computing the heat delivered to the zone and that lost to the outside, we have to account for the fact that in the absence of the distribution system, there would still be the heat-loss path $\mathrm{h}_{\mathrm{z}}$ in series with $h_{a}$ from the zone to the outside, which the distribution system masks. That is, if the hydronic system is off, the pipes will float at the temperature $T_{d}$. Since putting pipes in a room doesn't increase the heat loss from the room when the system is not operating, it stands to reason that the heat loss from the system to the ambient under these conditions should come out to be zero. Similarly, the heat flow from the system to the room should equal zero. But because of the above-mentioned series heat-flow path, Equations 8 and 9 will not yield zero values. We therefore should subtract from $\Delta Q_{\mathrm{a}}$ and add to $\Delta Q_{\mathrm{z}}$ the amount of this series heat flow, which is given by 


$$
\frac{h_{z} h_{a}}{h_{a}+h_{z}}\left(T_{z}-T_{a}\right) x=\frac{m_{t} k_{a} k_{z}}{k}\left(T_{z}-T_{a}\right) x
$$

By using the definition of $T_{d}$ along with some algebra, it is possible to show that the right hand side of Equation 12 is equal to $m_{1} k_{a}\left(T_{d}-T_{a}\right) x$, and it is also equal to $-m_{t} k_{z}\left(T_{d}-T_{z}\right) x$. But now we can see that by subtracting the former expression from Equation 8, as prescribed above, and adding the latter expression to Equation 9, the first term to the right of the equal sign in each equation is removed, which simplifies them both, and yields results in which the heat flow from the hydronic system to either the zone or the ambient is zero if the system is shut down $\left(T_{0}=T_{d}\right)$. The simplified expressions for $\Delta Q_{\mathrm{a}}$ and $\Delta \mathrm{Q}_{\mathrm{z}}$ are then:

$$
\begin{aligned}
& \Delta Q_{\mathrm{a}}=\frac{m_{t} k_{a}}{k}\left(T_{0}-T_{d}\right)\left(1-e^{-k x}\right) \\
& \Delta Q_{z}=\frac{m_{t} k_{z}}{k}\left(T_{0}-T_{d}\right)\left(1-e^{-k x}\right)
\end{aligned}
$$

\section{Pipe-Water Equilibrium}

This section calculates the equilibrium temperature between a slug of water coming into a pipe section, and the pipe section itself. The assumptions are those of simple calorimetry.

$$
\begin{array}{lll}
\multicolumn{2}{c}{\text { Quantity }} & \text { Units } \\
\mathrm{T}_{\mathrm{w}}=\begin{array}{l}
\text { Temperature of water coming into } \\
\text { pipe section }
\end{array} & \mathrm{F} & \mathrm{C} \\
\mathrm{T}_{\mathrm{p}}=\begin{array}{l}
\text { Temperature of pipe section before } \\
\text { the move of water }
\end{array} & \mathrm{F} & \mathrm{C} \\
\mathrm{T}_{\mathrm{eq}}=\begin{array}{l}
\text { Equilibrium temperature of water and } \\
\text { pipe after the move }
\end{array} & \mathrm{F} & \mathrm{C} \\
\mathrm{m}_{\mathrm{tw}}=\text { Thermal mass of water } & \mathrm{Btu} / \mathrm{F} & \mathrm{kJ} / \mathrm{C} \\
\mathrm{m}_{\mathrm{p}}=\text { Thermal mass of pipe section } & \mathrm{Btu} / \mathrm{F} & \mathrm{KJ} / \mathrm{C} \\
\mathrm{m}_{\mathrm{t}}=\text { Thermal mass of water and pipe } & \mathrm{Btu} / \mathrm{F} & \mathrm{kJ} / \mathrm{C}
\end{array}
$$

The thermal masses are additive:

$m_{t w}+m_{t p}=m_{t}$ 
The enthalpies are additive:

$T_{w} m_{t w}+T_{p} m_{p p}=T_{e q} m_{t}$

Hence,

$T_{e q}=\left(T_{w} m_{t w}+T_{p} m_{p p}\right) / m_{t}$

\section{Boiler Heat Flows}

This section performs develops relationships that will permit calculations relating to the boiler to be performed.

Quantity

$\mathrm{T}_{\mathrm{bo}}=$ Initial boiler water temperature (BWT)

$T_{b}=B W T$ at a later time

$T_{z}=$ Temperature of zone in which boiler is located

$h_{j}=$ Jacket-loss UA (on or off cycle)

$\mathrm{h}_{\mathrm{s}}=$ stack-loss UA (off cycle only)

$h=h_{j}+h_{s}=$ overall UA (off cycle)

$\eta_{\mathrm{s}}=$ Steady-state stack efficiency

$\mathrm{m}_{\mathrm{b}}=$ Boiler thermal mass

$\dot{Q}=$ Net heat flow into boiler

$\dot{Q}_{\text {in }}=$ Fuel input rate
Units<smiles>[3H]</smiles>

F C

F $\quad$ C

Btu/h-F $\quad \mathrm{kJ} / \mathrm{h}-\mathrm{C}$

$\mathrm{Btu} / \mathrm{h}-\mathrm{F} \quad \mathrm{kJ} / \mathrm{h}-\mathrm{C}$

$-$

Btu/F

Btu/h

Btu/h $c$

c

$\mathrm{kJ} / \mathrm{C}$

$\mathrm{kJ} / \mathrm{h}$

$\mathrm{kJ} / \mathrm{h}$

1. Off Cycle

BWT Relaxation

$$
\begin{aligned}
T_{b}-T_{z} & =\left(T_{b o}-T_{z}\right) \exp \left(-h t / m_{b}\right) \\
T_{b} & =T_{z}+\left(T_{b o}-T_{z}\right) \exp \left(-h t / m_{b}\right)
\end{aligned}
$$

Time for BWT to relax to a given $T_{b}$

$\left(T_{b o}-T_{z}\right) /\left(T_{b}-T_{z}\right)=\exp \left(h t / m_{b}\right)$

$t=m_{b} / h \quad \ln \left[\left(T_{b o}-T_{z}\right) /\left(T_{b}-T_{z}\right)\right]$

stack, jacket losses

Total loss $\Delta Q=m_{b}\left(T_{b o}-T_{b}\right)$

stack loss $\Delta \mathrm{Q}_{\mathrm{s}}=\Delta \mathrm{Q} \mathrm{h}_{\mathrm{s}} / \mathrm{h}$

Jacket loss $\Delta Q_{j}=\Delta Q h_{j} / h$ 
2. On Cycle

Here we need to make some assumptions. We begin with the simple case where steady-state efficiency is a constant independent of BWT. (This is not strictly true, but should be all right if we work within a normal range of BWT variation.) We also assume that the instantaneous stack efficiency during the on-cycle is equal to the steady-state efficiency. This is also not strictly true, since it ignores startup conditions, but was found to fit data fairly well in a previous analysis. If we need a more complicated set of assumptions later we can always add them, but this should work well enough at this time.

We start with two equations for the instantaneous energy flow into the boiler:

$$
\begin{aligned}
& \dot{\mathrm{Q}}=\dot{\mathrm{Q}}_{\mathrm{in}} \eta_{\mathrm{s}}-\mathrm{h}_{\mathrm{j}}\left(\mathrm{T}_{\mathrm{b}}-\mathrm{T}_{\mathrm{z}}\right) \\
& \dot{\mathrm{Q}}=\mathrm{m}_{\mathrm{b}} D t_{\mathrm{b}} / \mathrm{dt}
\end{aligned}
$$

Let $\mathrm{W}=\mathrm{T}_{\mathrm{b}}-\mathrm{T}_{\mathrm{z}}-\dot{\mathrm{Q}}_{\mathrm{in}} \eta_{\mathrm{s}} / \mathrm{h}_{\mathrm{j}}$. Then,

$$
d W / d t=-\left(h_{j} / m_{b}\right) W
$$

This yields the usual solution

$$
W=W_{0} \exp \left(-h_{j} t / m_{b}\right)
$$

which translates to

$$
\begin{aligned}
& T_{b}-T_{z}-\dot{Q}_{i n} \eta_{s} / h_{j}=\left(T_{b o}-T_{z}-\dot{Q}_{i n} \eta_{s} / h_{j}\right) \exp \left(-h_{j} t / m_{b}\right) \\
& \text { For small } t \ll h_{j} / m_{b} \text {, once can check that } \\
& T_{b} \approx T_{b o}-\left(T_{b o}-T_{z}\right) h_{j} t / m_{b}+\dot{Q}_{i n} \eta_{s} t / m_{b}
\end{aligned}
$$

which represents initial BWT minus a linear drop due to jacket loss plus a linear rise due to heat input. For longer times, things aren't linear due to changing temperatures.

The time for $T_{b o}$ to rise to a certain temperature $T_{b}$ is:

$$
t=\frac{m_{b}}{h_{j}} \ln \frac{T_{b o}-T_{z}-\dot{Q}_{i n} \eta_{s} / h_{j}}{T_{b}-T_{z}-\dot{Q}_{i n} \eta_{s} / h_{j}}
$$

Net heat into the boiler is: 


$$
\Delta \mathrm{Q}=\mathrm{m}_{\mathrm{b}}\left(\mathrm{T}_{\mathrm{b}}-\mathrm{T}_{\mathrm{bo}}\right)
$$

Heat put in by the burner over a time $t$ is given by:

$$
\Delta \mathrm{Q}_{\text {burm }}=\dot{\mathrm{Q}}_{\text {in }} \eta_{\mathrm{s}} t
$$

The jacket loss is the difference between these two quantities

$$
\begin{aligned}
\Delta Q_{j a c} & =\Delta Q_{b u r m}-\Delta Q \\
& =\dot{Q}_{\text {in }} \eta, t-m_{b}\left(T_{b}-T_{b o}\right)
\end{aligned}
$$

We can check this expression for small $t$ :

$$
\begin{aligned}
\Delta Q_{j a c}= & \dot{Q}_{\text {in }} \eta_{s} t-m_{b}\left(T_{z}-\dot{Q}_{\text {in }} \eta_{s} / h_{j}-T_{b o}\right)\left[1-\exp \left(-h_{j} t / m_{b}\right)\right] \\
& \approx \dot{Q}_{\text {in }} \eta_{s} t-m_{b}\left(T_{z}-\dot{Q}_{\text {in }} \eta_{s} / h_{j}-T_{b o}\right)\left(h_{j} t / m_{b}\right) \\
& =m_{b}\left(T_{b o}-T_{z}\right) t
\end{aligned}
$$

which is what it should be for short times when the boiler water temperature has not deviated much from $\mathrm{T}_{\mathrm{bo}}$ !

Comparison of Two Methods to Model Heat Flows in Hydronic systems

This analysis compares two alternative methods that have been proposed to model the heat flows from pipes in hydronic heating systems. The two methods are termed here the "block approach" and the "end-points approach." The block approach follows discrete "chunks" of water as the move around the loop, somewhat like linked sausages, while the end-points approach keeps track of the temperatures at evenly spaced points on the pipe loop, like stationary sentries watching a river go by.

Block Approach. The block approach is incorporated in the flow charts and program language previously included in discussions of this project. In the block approach, the water in the pipe loop is divided into blocks of equal volume, each of which is characterized by a temperature that varies over time as the block moves through the loop. The model is set up in such a way that the blocks make discontinuous jumps between timesteps, and each timestep is sufficiently long that the size of the jump is just enough to get each block into the space previously occupied by the block ahead of it. An initial wait of one-half timestep is included in the algorithm, so that the jumps effectively occur in the middle of the timesteps.

Because the blocks are considered to be stationary between jumps, we can model the heat. flow by means of the standard heatloss equation 


$$
\frac{d T}{d t}=-\frac{U A}{m c_{p}}\left(T-T_{z}\right)
$$

where $T$ is the temperature of the water in the block, $T_{z}$ is the temperature of the space surrounding the pipe, UA is the overall heat-flow coefficient between the block and the surrounding space, $m$ is the mass of a block of water, and $c_{p}$ is the specific heat of the water. For the moment we ignore the thermal mass of the pipe wall. This would be handled in somewhat different ways in the two approaches.

If $t_{\text {sec }}$ is the timestep, and $T_{0}$ and $T_{1}$ are the block temperatures at the beginning and end of a period of time in which the blocks are stationary, then

$$
T_{1}=T_{z}+\left(T_{0}-T_{z}\right) \exp \left(-\frac{U A}{m c_{p}} t_{s e c}\right)
$$

If $\dot{m}$ is the flow rate of the water $(1 \mathrm{~b} / \mathrm{h}$ or $\mathrm{kg} / \mathrm{h})$ then the timestep is related to $m$ and $\dot{m}$ by the equation $m=\dot{m} t_{s e c}$.

End-Points Approach. The end-points approach makes use of the log-mean temperature difference between the water and the surrounding zone, together with the temperature drop experienced by the water as it passes through a pipe segment. Two equations for the heat flow $\dot{Q}$ from the pipe section are:

$$
\dot{Q}=U A \Delta T_{\log -\text { mean }}=U A \frac{T_{0}-T_{1}}{\ln \left(\frac{T_{0}-T_{z}}{T_{1}-T_{z}}\right)}
$$

and

$$
\dot{Q}=\dot{m} c_{p} \Delta T=\dot{m} c_{p}\left(T_{0}-T_{1}\right)
$$

Eliminating $\dot{Q}$ from these equations yields:

$$
\frac{U A}{\dot{m} c_{p}}=\ln \left(\frac{T_{0}-T_{z}}{T_{1}-T_{z}}\right)
$$

This can be solved for $T_{1}$ with the result: 


$$
T_{1}=T_{z}+\left(T_{0}-T_{z}\right) \exp \left(-\frac{U A}{\dot{m} C_{p}}\right)
$$

We note the similarity of equations 2 and 6 .

An Example. We now do a sample calculation to see how the two methods compare. The calculations will be done in SI units, with approximate American equivalents given in parentheses.

We assume there are 6 pipe sections, all identical, each with a UA value of $90 \mathrm{~kJ} / \mathrm{h}-\mathrm{C}(50 \mathrm{Btu} / \mathrm{hr}-\mathrm{F})$. This permits a heat transfer of $32,400 \mathrm{~kJ} / \mathrm{h}(30,000 \mathrm{Btu} / \mathrm{h})$ for $a \quad 60 \mathrm{C}(108 \mathrm{~F})$ temperature difference.

For realism, let us consider the pipe to be $3 / 4$ in. ID, with each section $20 \mathrm{ft}$ long. The volume of this section in SI units will be $0.001738 \mathrm{~m}^{3}\left(0.06 \mathrm{ft}^{3}\right)$. Each section will contain $1.738 \mathrm{~kg}$ $(3.8 \mathrm{lb})$ of water. If we specify a flow rate of $450 \mathrm{~kg} / \mathrm{h}(1000$ $\mathrm{lb} / \mathrm{h}$ or $2 \mathrm{gpm}$ ) this will be sufficient to support the heat release rate specified in the preceding paragraph at a temperature drop of $17.20 \mathrm{C}(31 \mathrm{~F})$, since the SI specific heat of water is $4.186 \mathrm{~kJ} / \mathrm{C}$.

Since the volume of $450 \mathrm{~kg}$ of water is $0.45 \mathrm{~m}^{3}$, this allows us to calculate the timestep associated with these assumptions:

$$
t_{\text {sec }}=v / \dot{v}=0.001738 / 0.45=0.003862 \mathrm{~h}=13.90 \text { seconds } .
$$

Now let us calculate the groups in the exponentials in Equations 2 and 6:

Equation Group Calculation

$2 \quad \mathrm{UA} / \dot{\mathrm{m}} \mathrm{c}_{\mathrm{p}} \quad 90 /(450 \times 4.186)=0.04778$

$6 \quad \mathrm{UAt}_{\mathrm{sec}} / \mathrm{mc}_{\mathrm{p}} \quad 90 \times 0.003862 /(1.738 \times 4.186)=0.4778$

So now we can calculate the exponential $\exp \left(-\mathrm{UA} / \dot{\mathrm{m}} \mathrm{c}_{\mathrm{p}}\right)=$ $\exp \left(-U A t_{s e c} / \mathrm{mc}_{\mathrm{p}}\right)=0.9533$. Also, for the block approach we will need $\exp \left(-U A / 2 \mathrm{mC}_{\mathrm{p}}\right)=0.9764$. 
Successive powers of 0.9533 are:

$$
\begin{aligned}
& 0.9533 \\
& 0.9089 \\
& 0.8665 \\
& 0.8260 \\
& 0.7875 \\
& 0.7508
\end{aligned}
$$

For our test case the water in the pipe starts at $20 \mathrm{C}$, while boiler water at $90 \mathrm{C}$ is ready to start feeding into the pipe. As shown in Figure A1-1, for the end-points approach, with each timestep the warm water progresses one section, losing heat as it does so. By the end of timestep 6 , the water temperatures at the section boundaries have achieved an exponentially decreasing profile which they will retain there on out.

The block approach, in contrast, is shown in Figure A1-2. This is a somewhat busier chart, and requires some explanation. The half-timestep pipe states have a split set of temperatures. This is because of the sudden shift that occurs at these times. The temperature before the slash is that just before the shift, while the temperature after the slash is that just after the shift.

Heat loss between half-timestep points occurs at a rate consistent with the end-points approach. The dotted arrows show how the numbers in a typical box are generated. The first number (pre-shift) reflects heat loss relative to the (post-shift) value immediately above. The second number (post-shift) comes from the pre-shift value of the block immediately to its left.

The last half timestep (from 5.5 to 6.0 ) represents heat loss of the stationary blocks for that half timestep. The final temperatures can be considered to be the temperature at the midpoint of the block. The values obtained in this way can be seen to be consistent with the end-point temperatures in Figure A1-1, forming a smooth, continuous curve with them. 


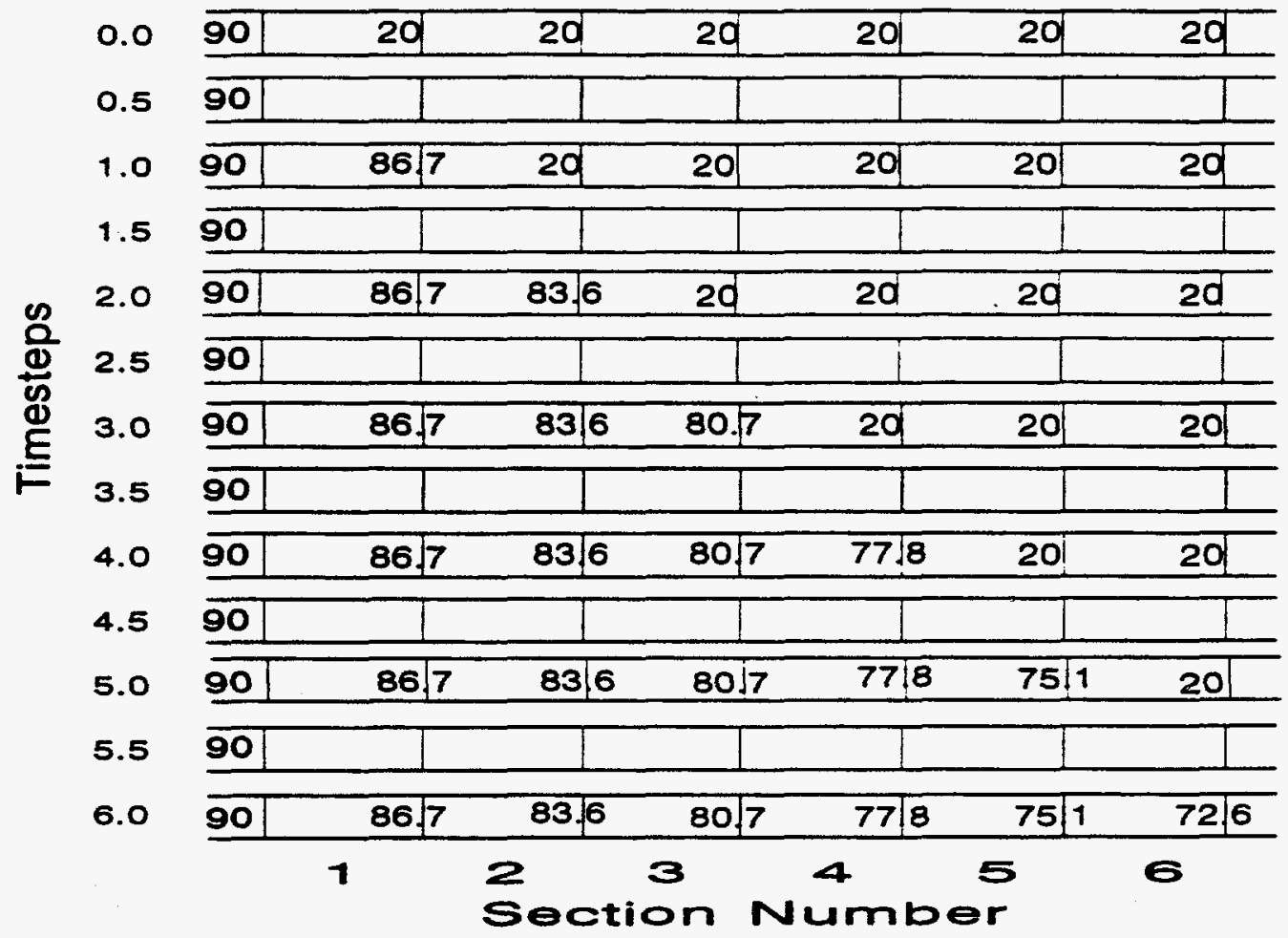

Figure A1-1. Temperatures in pipes for the end-points approach.

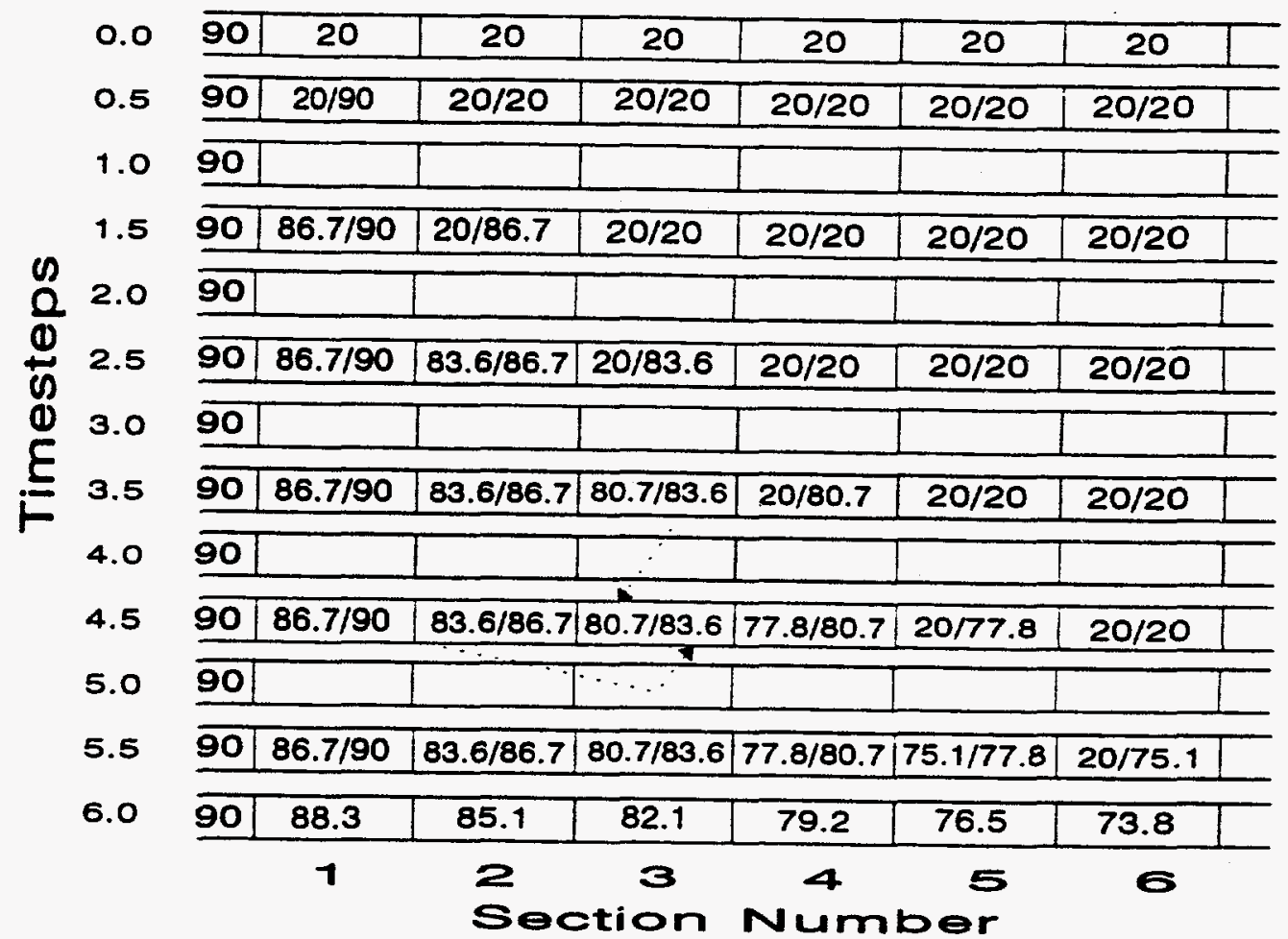

Figure A1-2. Temperatures in pipes for the block approach. 
APPENDIX 2. HYDRONIC PROGRAM CODE

A verbatim transcript of the program code used in this project, as of october 5, 1994, is included here. This code was used to obtain the results for the 24-hour runs reported on in the above text. The code is divided into three main sections: hydro.bas, loadcurv.bas, and hydronic.inc.

Hydro.bas contains the main program. Loadcurv.bas is the "front end" that computes the expected number of cycles per hour and fractional on-time corresponding to any given hourly heating load. It is run once at the beginning of a heating season's simulation; the table it generates then determines the cycling behavior in all subsequent hours. Hydronic.inc contains the subroutines called by the other two programs. Aside from "housekeeping" routines, these are:

- CIRCPROF: Determines the circulator pump on-off times from the percent-ontime \& cycle information obtained from the "front-end" table.

- PLUGSHIFT: Moves the slugs of water forward 1 section and mixes boiler water.

- HXON: Calculates heat transfer when the circulator is on.

- HXOFF: Calculates heat transfer when the circulator is off.

- BOILER: Determines the heat flows for the boiler; calls two additional routines below.

- BOILERON: Subroutine for BOILER; handles the burner-on period.

- BOILEROFF: Subroutine for BOILER; handles the burner-off period.

\section{PROGRAM: HYDRO.BAS}

This program models the thermal performance of a hydronic heating system where the system piping passes through two zones. Zone 1 is the buffer (non living) space and zone 2 is the conditioned space. The heating load that the program uses comes from the program DOE-2. This heating load is assumed to apply to the conditioned zone only.

'PROGRAM NOTES:

1) The variables in the program follow the standard FORTRAN 'naming conventions: variables beginning with the letters I through ' $N$ are integers, all others are assumed to be single precision 'floating point values.

Initialization section for main hydronic program; INIT in flowcharts.

'Variables are declared (set to some default value) 
CLEAR

DEFINT I-N

DEFSNG $\mathrm{A}-\mathrm{H}, \mathrm{O}-\mathrm{Z}$

$\because D E B U G M O D E O F F=1$
' ZERO OUT MEMORY

'DEFAULT INteger type

'DEFAULT SiNGle precision floating point 'SET TO O FOR DEBUGGING CODE ON, OTHERWISE

'FLAG: IS THE CIRCULATOR PUMP ON OR NOT

'FLAG: IS THE BOILER ON OR OFF

'generic loop counter

' integer dummy variable

'floating point

'dummy variables

'dummy string variable

input file name

'output file name

' fractional ontime profile file

'steady state operations flag

A $\$=$ "Hour=\#\# Time= \#.\#\# (min) Boiler Temp.=\#\#.\#(F) circ= \# Boiler= \#"

B\$="Boiler ops: Stack=\#,\#\#,\#\#\# Jacket=\#,\#\#\#,\#\# Fuel=\#,\#\#,\#\#\# Net=\#\#\#,\#\#"

$c \$="$ Heat delivered to dist system=\#,\#\#\#,\#\#.\#\#"

$\mathrm{D} \$=$ "Heat into: $\mathrm{z} 1=$ \#,\#\#,\#\#\# $\mathrm{z2}=\#$ \#,\#\#,\#\#\# Amb1= \#,\#\#,\#\# Amb2=\#, \#\#\#,\#\#"

E\$="sect TWin Twout Tpipe Heat Acc. (pipe) Heat Acc.

(water)"

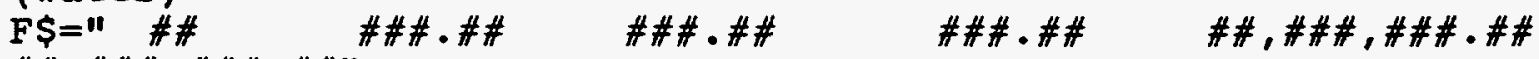

\#\#,\#\#,\#\#\#・\#"











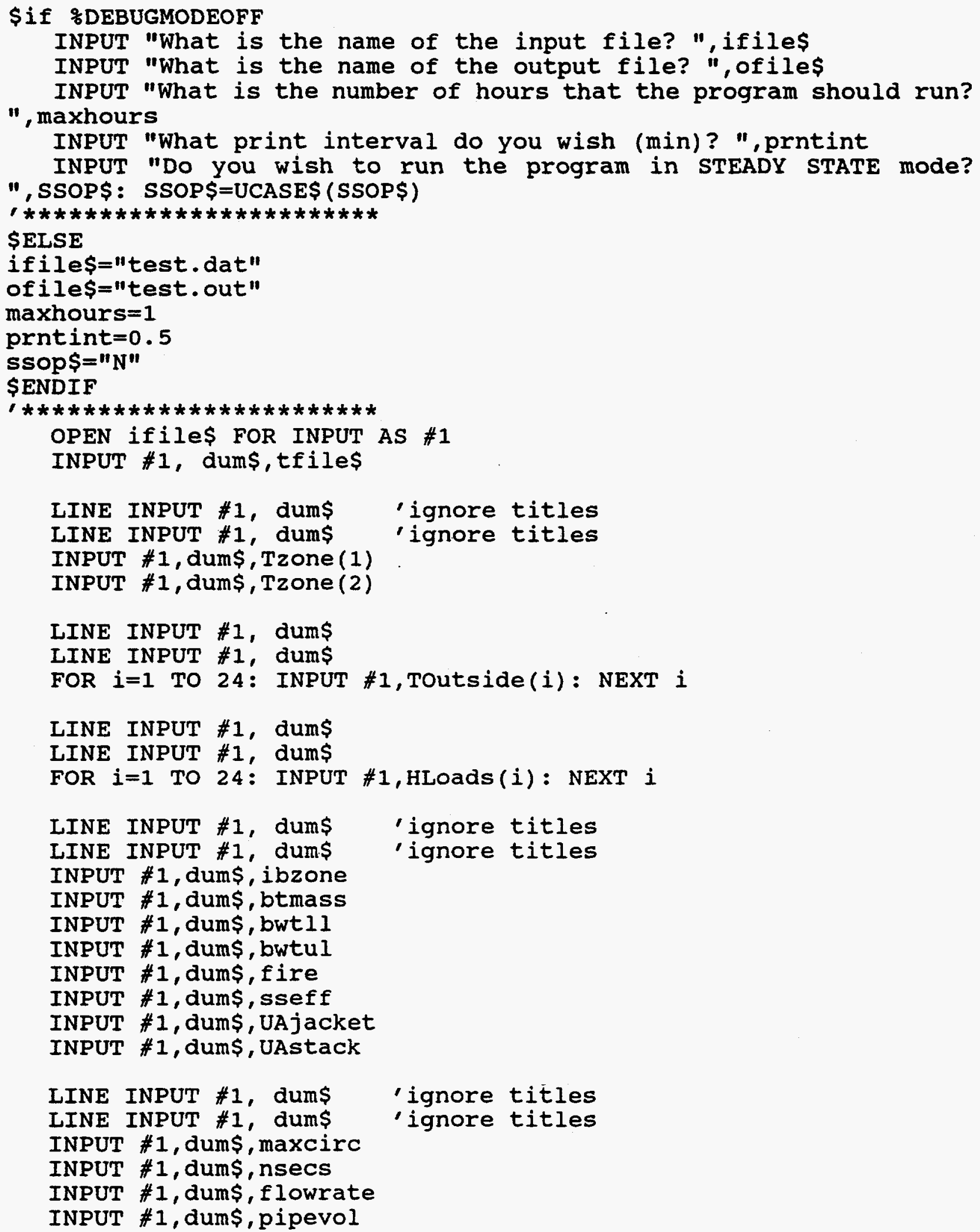




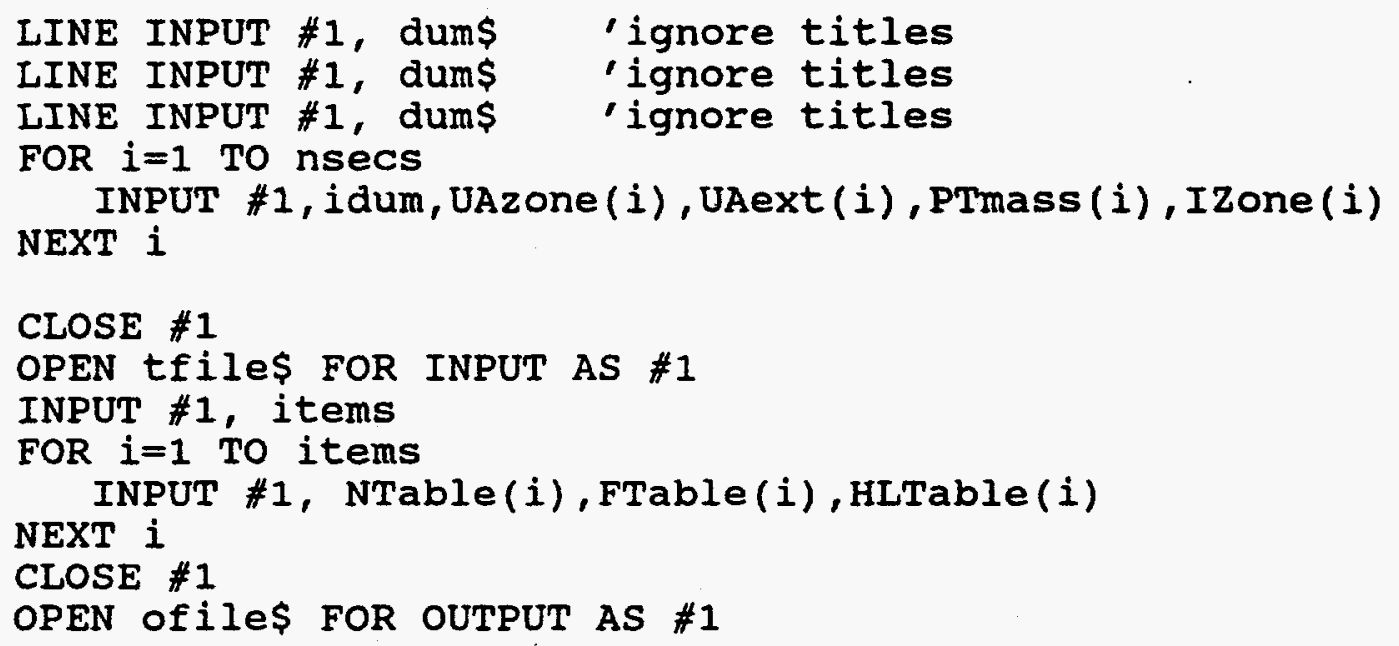

'now calculate the remainder of the variables needed to start

' - - - - - - -

prntint $=$ prntint $* 60$

wtmass $=$ rhocp $*$ pipevol

dthx $=3600 *$ pipevol/flowrate

FOR $i=1$ TO nsecs

TTmass $(i)=$ PTmass $(i)+$ wtmass

NEXT $i$

INCR dummyl, ( wtmass*Tzone( Izone(i) ) )



CALL STEADYSTATE(TWin(), TWout(), Tpipe())

FOR HOUR=1 TO MAXHOURS

Nextprint $=0$

Rfuel=0: Rjacket=0: Rstack=0: icntcyc=1: Rboiler=0

ERASE Rzone(), Ramb(), Qzone (), Qamb()

carryover $=0$

time $=0$

CALL PRNT2FILE (1)

CALL PRNT2SCRN

hload=HLoads (HOUR)

IF SSOP\$="N" THEN

ELSE

CALL LOOKUPTBL (hload, ncyc, fracton)

ncyc $=1$ : fracton $=1$ !

END IF 
CALL CIRCPROF( ncyc, fracton, $\operatorname{circon}(), \operatorname{circoff}())$

FOR time $=1$ TO 3600 step dthx

Qjacket $=0$ : Qstack $=0$ : Qfuel $=0$

Qboiler $=0$ : Qboiler $2=0$

iscircon $=0$

THEN

IF time>circoff (icntcyc) AND (time-dthx) $<=\operatorname{circoff}$ (icntcyc)

END IF

IF (time>=Circon(icntcyc) AND time<Circoff(icntcyc)) THEN iscircon $=1$

END IF

CALL PLUGSHIFT( nsecs, TWin(), TWout(), bwt, Qboiler )

FOR $i=1$ TO nsecs

dummy $1=0:$ dummy $2=0:$ dummy $3=0:$ dummy $4=0$

IF iscircon THEN

$\begin{array}{llllllllll}C & A & L & L & H & X & O & N & (\end{array}$

TWin(i) , TWout (i) , Tpipe (i) , dummy 1, dummy 2, dummy3, dummy 4, $i$, dthx)

ELSE

TWin(i), Twout (i), Tpipe (i), dummy 1, dummy 2 , dummy 3 , dummy $4, i, \operatorname{dth} x$ )

C A L L $\quad$ H $X$ O

END IF

INCR Qzone(i), dummy 1

INCR Qamb(i), dummy2

INCR Rzone( Izone(i) ), dummy1

INCR Ramb( IZone(i) ), dummy2

Waternet $(i)=$ dummy 3

NEXT i

INCR Pipenet(i), dummy 4

IF SSOP $\$=" N "$ THEN ELSE

CALL BOILER (dthx, bwt, isboileron, Qfuel, Qjacket, Qstack)

bwt=bwtorig: Qfuel=0!: Qjacket=0!: Qstack $=0$ !

END IF

INCR Rfuel, Qfuel

INCR Rjacket, Qjacket

INCR Rstack, Qstack

INCR Rboiler, Qboiler

CALL PRNT2SCRN

IF time>=Nextprint THEN

INCR Nextprint, Prntint

END IF

CALL PRNT2FILE(1) 


\section{IF SSOP\$="N" THEN}

CALL CHECKCIRC ( (3600-time), hload, isboileron, isdone)

IF isdone THEN time $=3600$

END IF

NEXT time

IF isdone $=0$ THEN

IF ibzone $=2$ THEN dummy $1=R$ jacket ELSE dummy $1=0$

END IF

carryover $=($ Rzone $(2)+$ dummy 1$)$-hload

CALL PRNT2FILE (1)

PRINT \#1, USING "CARRYOVER= \#\#\#,\#\#\#\#\#; carryover

CALL PRNT2SCRN

print \#1," "

NEXT Hour

CLOSE \#1

END

Sinclude "hydronic.inc"

\$include "noises.inc"

'routine library

'warble \& alarm library

\section{LOADCURV.BAS}

'This program determines the behavior of a hydronic heating system.

'It acts as a preprocessor for the program hydro. Its main purpose

' is to generate runtime profile for a given hydronic system and

'save a table that relates fractional ontime, \# of circulator

'cycles, and heat delivered to the conditioned space (this last

'value excludes jacket losses). To determine the parameters for

'the table the program runs in steady state mode, where the boiler

'water is kept at a constant temperature.

'PROGRAM NOTES:

1) The variables in the program follow the standard FORTRAN ' naming conventions: variables beginning with the letters I through

' $N$ are integers, all others are assumed to be single precision

floating point values.

\section{CLEAR}

DEFINT I-N

DEFSNG $\mathrm{A}-\mathrm{H}, \mathrm{O}-\mathrm{Z}$

ISCIRCON $=0$

ISBOILERON $=$ IOFF

$i=0$

icnt $=0$

idum $=0$

dummy $1=0$ :

dummy $3=0$ :

dum $\$=" 1 "$

ifile $\$=" 1 "$

of ile $=" \|$



$\mathrm{B} S=" \# \#, \# \cdot \# \# \# \#, \quad \# \# \# \# \# \cdot \# \# \#$

dummy $2=0$

dummy $4=0$
' ZERO OUT MEMORY

'DEFAULT INteger type

'DEFAULT SiNGle precision floating point

'FLAG: IS THE CIRCULATOR PUMP ON OR NOT

'FLAG: IS THE BOILER ON OR OFF

'generic loop counter

' another generic loop counter

- integer dummy variable

'floating point

'dummy variables

'dummy string variable

-input file name

- output file name

CYC $=\#$

FRACTION=\# \#\#\#" 





'Clear out random junk
ERASE Circoff(), Circon(), IZone (), PTmass()
ERASE Tpipe(), TTmass(), TWin()
ERASE TWout(), Tzone(), UAext(), UAzone()

'end of initialization section; now get setup information from file

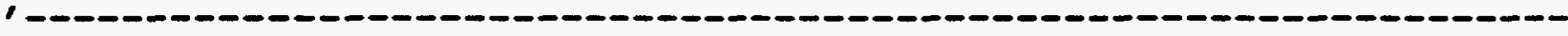

CLS

INPUT "What is the name of the input file? ", ifiles

OPEN ifile\$ FOR INPUT AS \#1

INPUT \#1, dum\$, ofile\$

LINE INPUT \#1, dum\$ 'ignore titles
LINE INPUT \#1, dum\$ ignore titles

INPUT \#1, dum\$, Tzone (1)

INPUT \#1, dum\$, Tzone (2)

LINE INPUT \#1, dum\$

LINE INPUT \#1, dum\$

FOR $i=1$ TO 24: INPUT \#1,TOutside(i): NEXT $i$

FOR $i=1$ TO 8

LINE INPUT \#1, dum\$

NEXT $i$

INPUT \#1, dums, ibzone

INPUT \#1, dum\$, btmass

INPUT \#1, dum\$, bwtll

INPUT \#1, dum\$, bwtul

INPUT \#1, dum\$, fire

INPUT \#1, dum\$, sseff

INPUT \#1, dum\$, UAjacket

INPUT \#1, dum\$, UAstack

LINE INPUT \#1, dum\$ 'ignore titles

LINE INPUT \#1, dumS 'ignore titles

INPUT \#1, dum\$, maxcycles

INPUT \#1, dum\$, nsecs

INPUT \#1, dum\$, flowrate

INPUT \#1, dum\$, pipevol

$\begin{array}{ll}\text { LINE INPUT \#1, dum\$ } & \text { 'ignore titles } \\ \text { LINE INPUT \#1, dum\$ } & \text { ignore titles } \\ \text { LINE INPUT \#1, dum\$ } & \text { 'ignore titles }\end{array}$

FOR $i=1$ TO nsecs NEXT i

INPUT \#1, idum, UAzone (i), UAext (i), PTmass (i), IZone (i)

CLOSE \#1

'now calculate the remainder of the variables needed to start

Tamb=0!: FOR $i=1$ TO 24: INCR Tamb,TOutside(i): NEXT i: $\mathrm{Tamb}=\mathrm{Tamb} / 24$ 
wtmass $=$ rhocp $*$ pipevol

dthx=3600*pipevol/flowrate

FOR $i=1$ TO nsecs

TTmass ( $i)=$ PTmass $(i)$ +wtmass

NEXT i

INCR dummy1, ( wtmass*Tzone( IZone(i) ) )

bwt $=$ (bwtul*btmass + dummy 1$) /($ btmass + nsecs*wtmass $)$

bwtorig=bwt

FOR $i=1$ TO nsecs

twin $(i)=b w t$

twout $(i)=b w t$

NEXT $i$

tpipe $(i)=b w t$ state

CALL STEADYSTATE(TIstart(), TIend(), TPstart()) 'Run in steady

CALL GETCYCLETBL(NTable(), maxcycles, items) 'build column 1 of profile

CALL GETFRACTIONTBL(FTable(), NTable(), maxcycles, items) 'build column 2 of profile

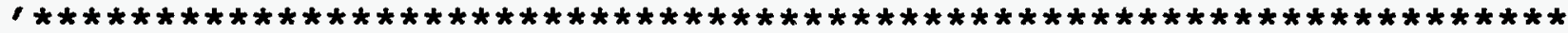

'Below is the code that generates the last column in the hydronic loop profile

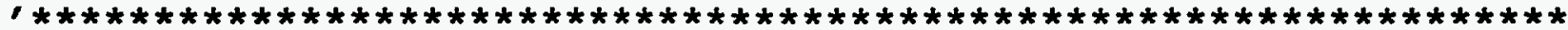

FOR icnt $=1$ TO items

ERASE Circon(), Circoff(), TWin(), TWout()

Qzone $=0$ : Qjacket $=0$ : icntcyc $=1$

FOR $i=1$ TO nsecs

TWin (i)=TIstart (i)

TWout $(i)=$ TIend $(i)$

bwt =bwtorig

NEXT i

CALL CIRCPROF( NTable(icnt), FTable(icnt), Circon(), Circoff()

FOR time=1 TO 3600 step dthx

PRINT USING A\$; icnt, time, NTable(icnt), FTable(icnt)

iscircon $=0$

THEN

IF time>circoff (icntcyc) AND (time-dthx) $<=\operatorname{circoff}$ (icntcyc)

END IF

IF time>=Circon(icntcyc) AND time<circoff(icntcyc) THEN iscircon $=1$

CALI PLUGSHIFT( nsecs, TWin(), TWout(), bwt, dummy1)

END IF

FOR $i=1$ TO nsecs

dummy $1=0:$ dummy $2=0:$ dummy $3=0:$ dummy $4=0$ 
IF iscircon THEN

C A L L . H X O N (

Twin (i), TWout (i) , Tpipe (i), dummy 1, dummy 2 , dummy 3 , dummy 4, i, dthx) ELSE

C A I L $\quad H \quad X \quad O \quad F \quad F \quad($

Twin (i), Twout (i) ,Tpipe (i), dummy 1, dummy 2 , dummy 3 , dummy $4, i$, dthx)

END IF

IF IZone $(i)=2$ THEN INCR QZone, dummy 1

NEXT i

bwt $=$ bwtorig

' CALL BOILER (dthx, bwt, isboileron, dummy 1, dummy2, dummy3)

' IF ibzone=2 THEN INCR Qjacket, dummy 2

NEXT time

HLTable (icnt) $=Q$ zone $+Q j$ jacket

NEXT icnt

OPEN ofile\$ FOR OUTPUT AS \#1

PRINT \#1, items

FOR $i=1$ TO items

NEXT i

PRINT \#1,USING B\$;NTable(i), FTable(i), HLTable(i)

END

CLOSE \#1

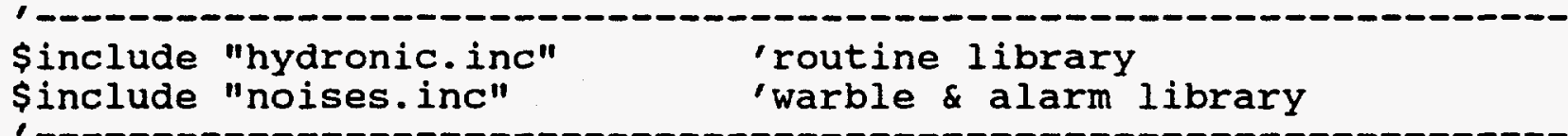

HYDRONIC. INC

\$IF 0

This file is hydronic.inc. It is a library file of all the routines that are needed by the hydronic.bas program. The list of routines included is listedbelow.

CIRCPROF: Determine the circulator pump on-off times from the \%ontime \& cycle info

PLUGSHIFT: Move the slugs of water forward 1 section \& mixes boiler water

HXON: Calculate heat transfer when the circulator is on

HXOFF: Heat transfer when the circulator is off

BOILER: Determine the heat flows for the boiler; "master" routine

BOILERON: Sub routine for BOILER; handles the boiler on period BOILEROFF: Sub routine for BOILER; handles the burner off period PRNT2SCRN: Generate Screen Display 
PRNT2FILE: Generate output file

\section{\$ENDIF}



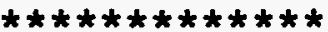

SUB CIRCPROF( nCYC, fract, circon(1), circoff(1) ) LOCAL LOCAL ontime, offtime, ondur, offdur, i SUB

IF ncyc=0 AND fract=1 THEN $\operatorname{circon}(1)=0: \operatorname{circoff}(1)=3600:$ EXIT

IF ncyc=0 AND fract $=0$ THEN EXIT SUB

ontime $=3600 *$ fract

ondur=ontime/ncyc

period

$\operatorname{circon}(1)=0$

circoff $(1)=$ ondur

offtime $=3600$-ontime

not run

offdur=offtime/ncyc

FOR $i=2$ TO ncyc

circon $(i)=\operatorname{circoff}(i-1)$ toffdur

$\operatorname{circof} f(i)=\operatorname{circon}(i)$ tondur

next i

END SUB 'circprof

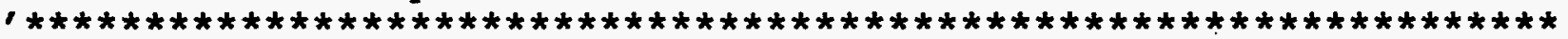

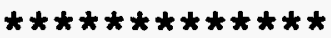

SUB PLUGSHIFT (nsecs, twin(1), twout (1), bwt, qboiler) LOCAL

SHARED btmass, wtmass, tpipe(),ptmass(), ttmass()

LOCAL i, bwt 1

bwt $1=b w t$

bwt $=$ ( twout (nsecs)*wtmass + bwt* (btmass-wtmass) ) /btmass

qboiler=wtmass* (bwt1-twout (nsecs))

FOR $i=$ nsecs TO 2 STEP -1

twin $(i)=\operatorname{twout}(i-1) \quad$ 'SHIFT PLUGS

twout $(i)=\operatorname{twin}(i)$

NEXT i

twin $(1)=$ bwt 1

twout (1)=twin (1)

END SUB 'plugshift

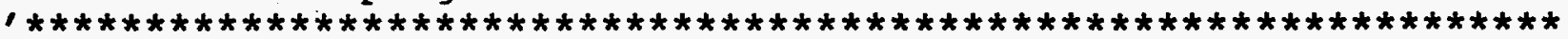

$\star \star * \star * * * * * * * * *$ 


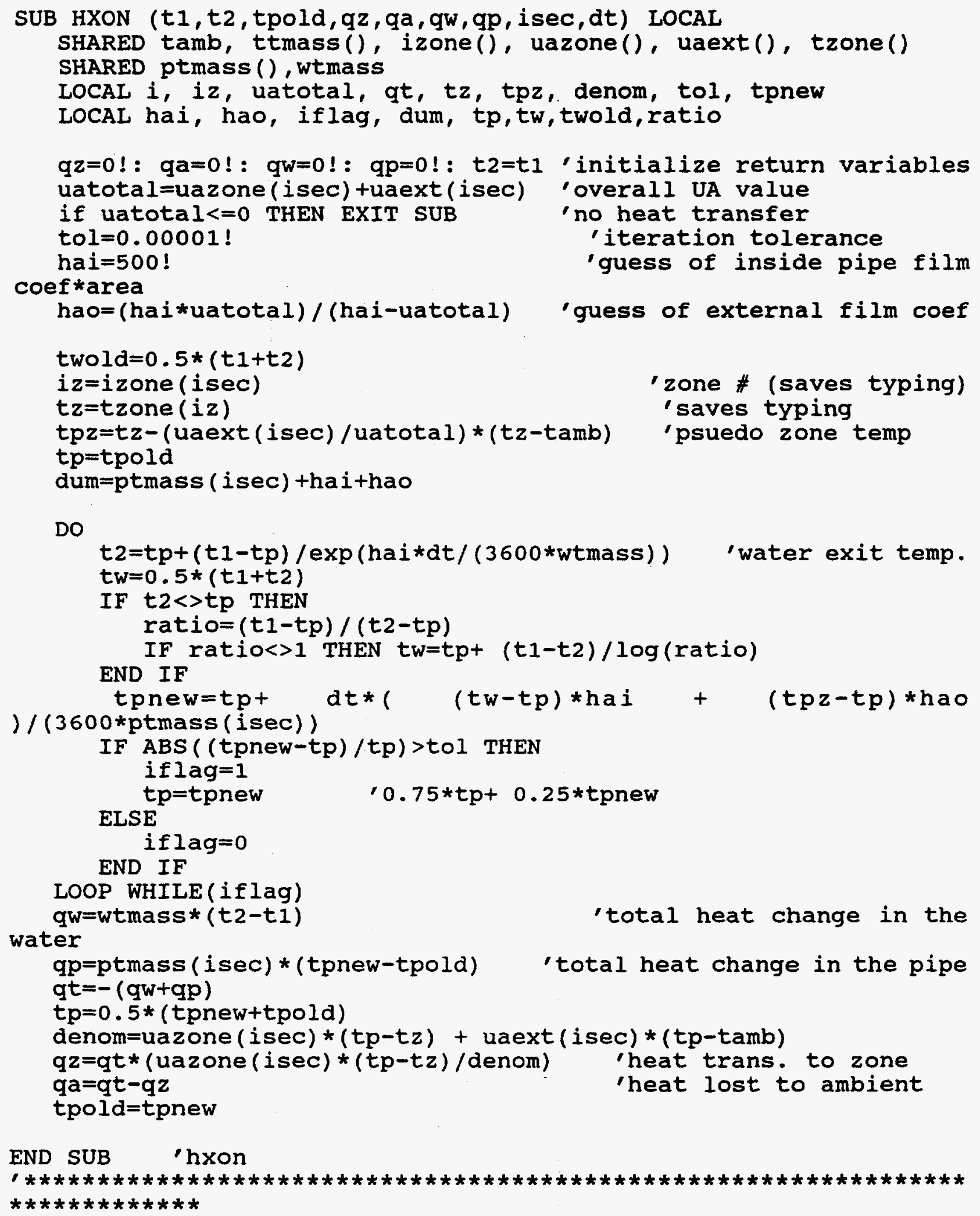

DO

$t 2=t p+(t 1-t p) / \exp ($ hai $* d t /(3600 * w t m a s s))$ 'water exit temp. 
SUB HXOFF (t1,t2,tpold, qz, qa, qw, qp, isec,dt) LOCAL SHARED tamb, izone(), uazone (), uaext (), tzone(), wtmass, ptmass ()

LOCAL iz, uatotal, qt, tz, twold, twnew, tpnew LOCAL hai, hao, tpseudoz, tol, alpha, beta, gamma, dum

values $q z=0$ ! : $q a=0 !: q w=0 !: q p=0 !:$

'initialize return uatotal=uazone (isec) +uaext (isec)

IF uatotal $<=0$ THEN EXIT SUB tol $=0.001$ !

hai $=2 ! *$ uatotal

hao=(hai*uatotal)/(hai-uatotal)

iz=izone (isec)

$t z=t z o n e(i z)$

'overall UA value

'must be revisited!!!

'zone \# (saves typing)

'zone temp. (ditto)

IF ( $t 1<=t$ pold oR $t 2<=t p o l d$ oR $t 1=t 2)$ THEN $t w o l d=0.5 *(t 1+t 2)$

ELSE

twold $=(t 1-t 2) / \log ((t 1-t p o l d) /(t 2-t p o l d))+t p o l d$ END IF

IF abs $(1-t w o l d / t z)<0.001$ ! AND abs $(1-t p o l d / t z)<0.001$ ! THEN

$t 1=t z: t 2=t z: t p=t z$ EXIT SUB

END IF

tpz=tz-(uaext (isec)/uatotal)*(tz-tamb) 'psuedo zone temp alpha=hai*dt/(3600*ptmass (isec) )

beta=hao*dt/( $3600 *$ ptmass (isec) )

gamma $=$ hai*dt/( $3600 *$ wtmass $)$

dum=tpold + beta*tpz $+($ alpha $/(1+$ gamma $)) *$ twold

tpnew=dum/ (1+alpha+beta-alpha*gamma/(1+gamma) )

twnew $=($ gamma $*$ pnew + twold $) /(1+$ gamma $)$ pipe

qp=ptmass (isec) * (tpnew-tpold) water

$q w=w t m a s s *(t w n e w-t w o l d)$

amb

$q t=-(q w+q p)$

'total heat change in the 'total heat change in the 'total heat trans. to zone \&

tpold $=0.5 *(t p n e w+t p o l d)$

denom=uazone (isec)* (tpold-tz) + uaext (isec)* (tpold-tamb)

$q z=q t *$ (uazone (isec)*(tpold-tz)/denom) 'heat trans. to zone

$q a=q t-q z$

'heat lost to ambient

$t 2=t 2+(t w n e w-t w o l d)$

tpold=tpnew

IF $t 2<t$ pnew THEN

$t 2=t p n e w$

ELSE

$t 1=2 ! * t w n e w-t 2$

$t 1=t 1+(t w n e w-t w o l d)$

END IF

END SUB

'hxoff

'update $t 1 \& t 2$ to

'reflect the relaxation over time dt

'returned value of pipe temp. 
SUB BOILER (duration, bwt, isboileron, qfuel,qjacket, qstack) LOCAL SHARED bwtll, bwtul, fire,bwtorig

LOCAL timeleft, ison, $q f, q j, q s$

timeleft=duration 'time left in the current sub call

Do WHILE (timeleft $>0$ )

$q f=0: q j=0: q s=0$

ison $=0$

IF bwt<=bwtll oR (isboileron AND bwt<bwtul) THEN ison=1 ELSE

IF fire $=0$ THEN ison=0

IF ison THEN 'the boiler is running

ELSE

CALL BOILERON(timeleft, bwt, qf,qj,qs)

CALI BOIIEROFF(timeleft, is not running

END IF 'ison if

INCR qfuel,qf

INCR qjacket,qj

INCR qstack, qs

LOOP 'end timeleft loop

isboileron $=$ ison

END SUB 'boiler

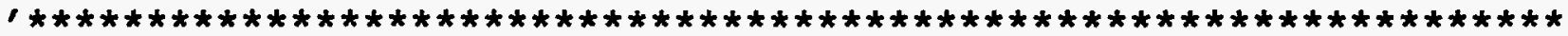



SUB BOILEROFF ( $t$ ime, bwt, qf, qj,qs) LOCAL

SHARED bwt ll, btmass, uastack, uajacket, ibzone, tzone ()

LOCAL time2ll, uatotal, qacc, $t 2, t z$, dumtime

$q f=0: q j=0: q s=0$

$t z=t z$ one (ibzone)

uatotal=uastack+uajacket

IF uatotal $l<=0$ THEN

time $=0$

EXIT SUB

END IF 'uatotal

IF bwt<tz THEN

CALL ALARM

PRINT "ERROR: bwt<tz in boileroff" STOP

END IF 'bwt

time $211=3600 *($ btmass/uatotal) $* \log (($ bwt $-t z) /($ bwt $11-t z))$

IF bwt<=bwtll THEN time2ll=time+1

IF time2ll<=time THEN

$t 2=b w t 11$

dumtime=time2ll

ELSE

$t 2=t z+($ bwt $-t z) / \exp ($ uatotal*time/(3600*btmass) )

dumtime=time

IF $t 2<t z$ THEN 
SUB CHECKCIRC( duration, hload, isboileron, ireturnvalue) LOCAL SHARED twin(), twout(), nsecs, bwt, ibzone, carryover SHARED qfuel, qjacket, qstack, tpipe(), Qzone(), Qamb() SHARED izone(), Rfuel, Rjacket, Rstack, Rboiler, Rzone(), Ramb()

LOCAL $i, b w t 2, \operatorname{tl}(), \operatorname{tr}(), \operatorname{tpw}(), q z n(), q$ loss (), iboiler LOCAL qf, qs, qj, d1, d2, d3, d4, zone1, zone2, heat 2 zone DIM tl(1:50), $\operatorname{tr}(1: 50), \operatorname{tpw}(1: 50), q z n(1: 50), q$ loss $(1: 50)$

bwt 2=bwt

ireturnvalue $=1$

iboiler=isboileron

FOR $i=1$ TO nsecs

$\operatorname{tl}(i)=\operatorname{twin}(i)$

$\operatorname{tr}(i)=\operatorname{twout}(i)$

tpw $(i)=$ tpipe $(i)$

CALL HXOFF ( $\operatorname{ll}(i), \operatorname{tr}(i), \operatorname{tpw}(i), d 1, d 2, d 3, d 4, i$, duration)

IF izone $(i)=1$ THEN INCR zone1, d1 ELSE INCR zone2,d1 $\operatorname{qzn}(i)=\mathrm{di}$

qloss $(i)=d 2$

NEXT i

CALL BOILER (duration, bwt, isboileron, qf, qj, qs)

IF ibzone $=2$ THEN heat 2 zone $=$ Rzone $(2)+q j+R j$ acket

heat2zone $=$ Rzone $(2)$ + heat2zone + zone2

IF heat2zone<hload THEN

bwt $=$ bwt 2

ireturnvalue $=0$

isboileron=iboiler

ELSE

ireturnvalue $=1$

INCR Rzone(1), zonel

INCR Rzone (2), zone2

INCR Rfuel, gf

INCR Rjacket, qj

INCR Rstack, qs

INCR Rboiler, Qboiler

FOR $i=1$ TO nsecs

$\operatorname{twin}(i)=t l(i)$

twout $(i)=\operatorname{tr}(i)$

tpipe $(i)=\operatorname{tpw}(i)$

Qzone $(i)=q z n(i)$

NEXT i

Qamb $(i)=q$ loss $(i)$

END IF

carryover=heat 2 zone-hload

END SUB

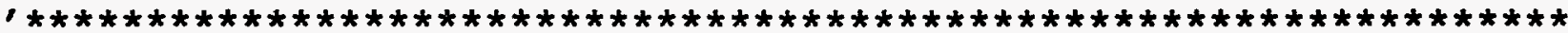

$\star * * * * * * * * * * * * *$ 
SUB STEADYSTATE(T1(1),T2(1),TP(1)) SHARED 'DETERMINE STEADY STATE VALUES

LOCAL i, irun, Texit, d1, d2 , d3 , d4

\section{irun $=0$ \\ Texit $=$ TWout (nsecs)}

DO

CALL PLUGSHIFT( nsecs, TWin(), TWout (), bwt, dummy1)

FOR $i=1$ TO nsecs

dummy $1=0:$ dummy $2=0:$ dummy $3=0:$ dummy $4=0$

NEXT i

CALI HXON( TWin(i), TWout (i), Tpipe (i), d1, d2,d3,d4, i,dthx)

bwt=bwtorig

IF ABS (TWout (nsecs)-Texit) $<0.0001$ THEN

FOR $i=1$ TO nsecs

T1 $(i)=$ TWin $(i)$

T2 $(i)=$ TWout $(i)$

TP $(i)=$ TPipe $(i)$

irun=1

NEXT i

END IF

Texit=Twout (nsecs)

LOOP UNTIL irun

END SUB

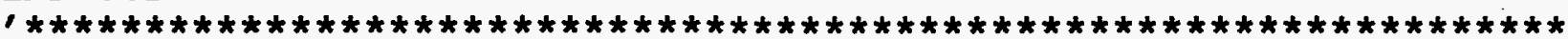

SUB GETCYCLETBL (NT (1), mc, items) LOCAL

LOCAL i

items $=2 * m c+1$

FOR $i=1$ TO $(m c+1): N T(i)=i-1:$ NEXT $i$

FOR $i=(m c+2)$ TO items: $N T(i)=i$ tems-i: NEXT $i$

END SUB

\section{END SUB}

SUB GETFRACTIONTBL(FT(), NT(), mc, items) LOCAL

LOCAL i

FOR $i=1$ TO items

IF ( $i<=$ mc) THEN

ELSE

$\mathrm{FT}(\mathrm{i})=0.5 *(1 !-\operatorname{SQR}(1 !-\mathrm{NT}(\mathrm{i}) / \mathrm{mC}))$

\section{END IF}

$\operatorname{FT}(i)=0.5 *(1 !+\operatorname{SQR}(1 !-\mathrm{NT}(\mathrm{i}) / \mathrm{mc}))$

NEXT $i$

END SUB
$* * * * * * * * * * * * * * * * * * * * * * * * * * * * * * * * * * * * * * * * * * * * * * * * * * * * * * * * * * * * * * * *$

SUB LOOKUPTBL $(\mathrm{hl}, \mathrm{nC}, \mathrm{f})$ LOCAL

SHARED FTable(), HLTable(), NTable(), items

LOCAL $i, j$

IF $h l=>$ HLTable (items) THEN 'load is > than flat out running $\mathrm{nc}=1$ 


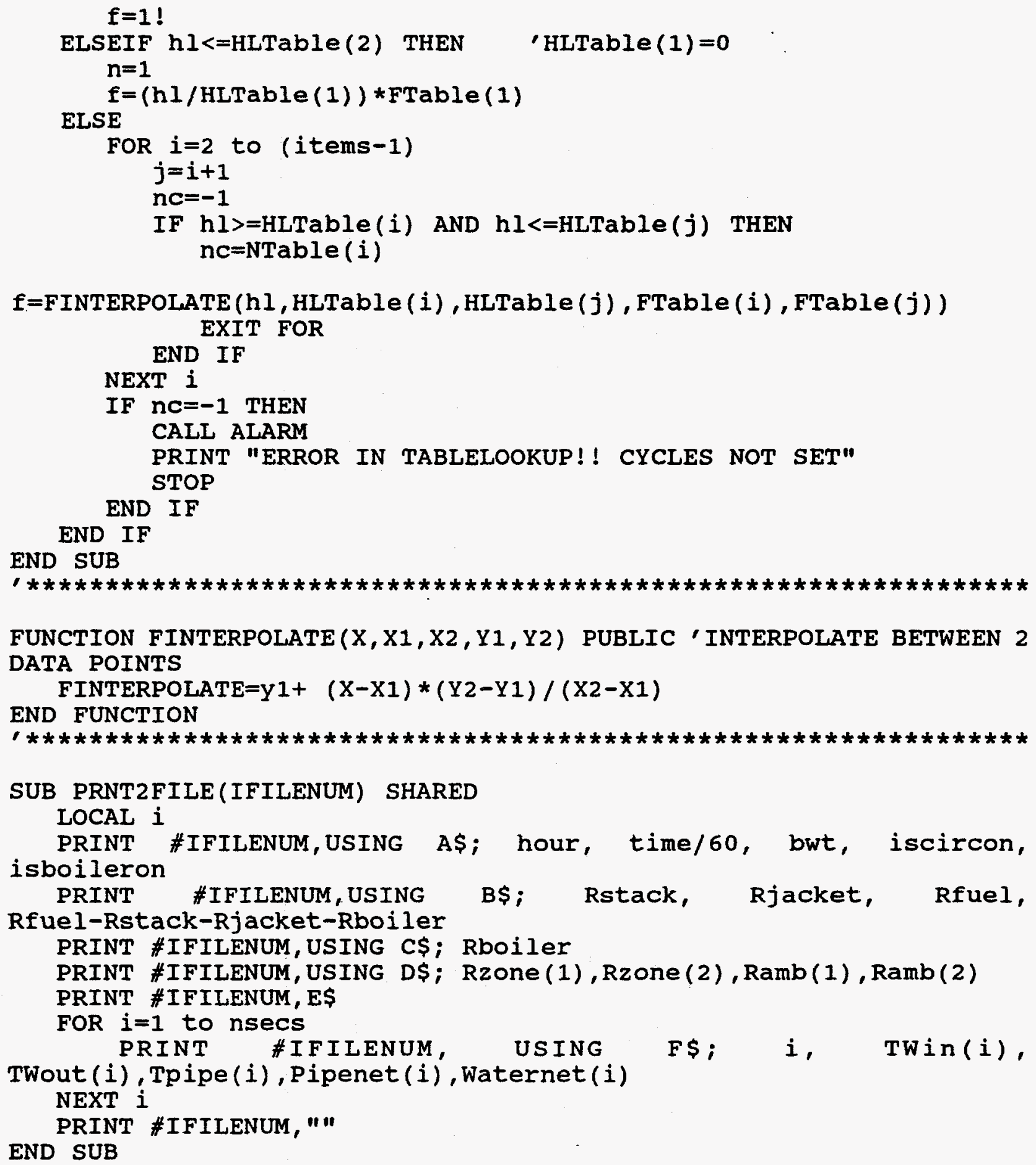

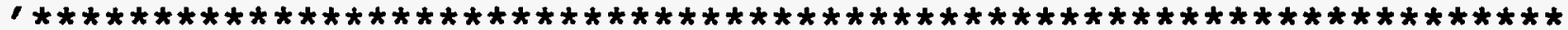

FUNCTION FINTERPOLATE $(X, X 1, X 2, Y 1, Y 2)$ PUBLIC 'INTERPOLATE BETWEEN 2 DATA POINTS

FINTERPOLATE $=\mathrm{Y} 1+(\mathrm{X}-\mathrm{X} 1) *(\mathrm{Y} 2-\mathrm{Y} 1) /(\mathrm{X} 2-\mathrm{X} 1)$ END FUNCTION



SUB PRNT2FILE(IFILENUM) SHARED

LOCAL i

PRINT \#IFILENUM, USING A\$; hour, time/60, bwt, iscircon, isboileron PRINT \#IFILENUM, USING B\$; Rstack, Rjacket, Rfuel, Rfuel-Rstack-Rjacket-Rboiler PRINT \#IFILENUM, USING C\$; Rboiler

PRINT \#IFILENUM, USING D\$; Rzone (1), Rzone(2), Ramb(1), Ramb (2) PRINT \#IFILENUM, E\$

FOR $i=1$ to nsecs PRINT \#IFILENUM, USING F\$; $i, \quad$ TWin(i), Twout (i), Tpipe (i), Pipenet (i), Waternet (i) NEXT i

PRINT \#IFILENUM, " " END SUB

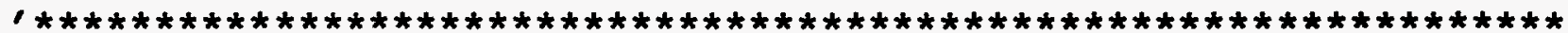


SUB PRNT2SCRN SHARED

LOCAL i

CLS

PRINT USING A\$; hour,time/60, bwt, iscircon, isboileron

PRINT USING BS; Rstack, Rjacket, Rfuel, Rfuel-Rstack-Rjacket-Rboiler

PRINT USING C\$; Rboiler

PRINT USING D\$; Rzone(1),Rzone(2), Ramb(1) ,Ramb(2)

PRINT E\$

FOR $i=1$ to nsecs

IF $i>16$ THEN EXIT FOR

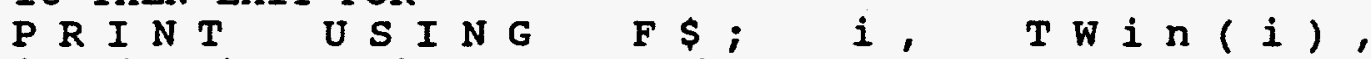

TWout (i),Tpipe (i), Pipenet (i), Waternet (i)

NEXT i

END SUB

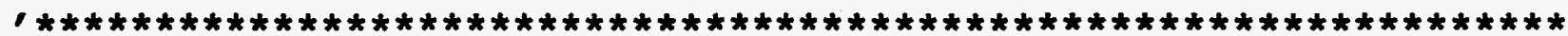




\section{REFERENCES}

Andrews, J. Impact of reduced firing rate on furnace and boiler efficiency. BNL 37226 , Oct. 1985.

ASHRAE (American Society of Heating, Refrigerating, and AirConditioning Engineers, Inc.). 1992 systems and Equipment Handbook. Chapter 29, Furnaces. Table 7 on page 29.13 describes a typical base case using a conventional natural-draft furnace. The system efficiency for this case is calculated to be 468 .

Jakob, F.E., R.D. Fischer, L.J. Flanigan, R.A. Cudnik, and D.W. Locklin. Dynamic and Seasonal Performance of Central Forced Air Systems Installed in Residences. Summary Report of ASHRAE Special Project SP43: Phases I and II: Heating. Final Report. Battelle Columbus Division, 505 King Avenue, Columbus, $\mathrm{OH}$ 43201. Detailed discussion of cycles per hour vs. fractional ontime is contained in unpublished data presented to the ASHRAE SP-43 Technical Evaluation Committee meeting at ottawa, Canada, June 27, 1988 .

RECS (Residential Energy Consumption Survey). Housing Characteristics 1990. U.S. DOE, Energy Information Administration report DOE/EIA-0314(90), MaY 1992. Table 28, page 80.

Treidler, B., M. Modera, and R. Jansky, 1993. A Simulation System for Buildings with Air Ducts. Lawrence Berkeley Laboratory report in press. 